SILVEIRA, S.R., FERREIRA, L.F.L. e LAGE, M.H.H. Fisiopatologia da sepse: revisão de literatura. PUBVET, Londrina, V. 8, N. 9, Ed. 258, Art. 1709, Maio, 2014.

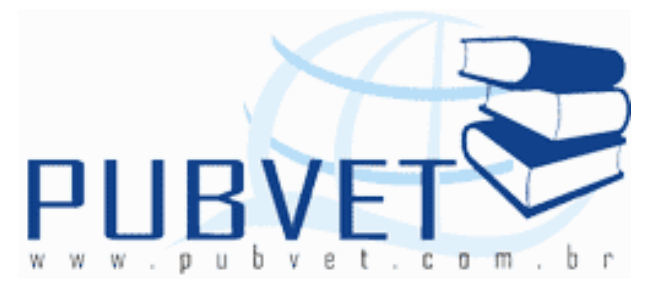

PUBVET, Publicações em Medicina Veterinária e Zootecnia.

\title{
Fisiopatologia da sepse: revisão de literatura
}

Sylvia Rocha e Silveira ${ }^{1}$, Luiz Fernando Lucas Ferreira ${ }^{2}$, Maíra H. H. Lage $^{3}$

${ }^{1}$ Médica Veterinária - Aluna do curso de pós-graduação em Bioengenharia de Sistemas Ecológicos da Universidade Federal de São João Del Rei (UFSJ) sylviarsilveira@yahoo.com.br

2 Médico Veterinário - Mestre em cirurgia pela Escola de Veterinária da Universidade Federal de Minas Gerais (UFMG) - Professor Assistente de Clínica e Cirurgia de Pequenos Animais do Curso de Medicina Veterinária da PUCMINAS

${ }^{3}$ Médica Veterinária autônoma

\section{Resumo}

A inflamação é uma reação fisiológica primária perante a agressão tecidual, seja ela de natureza física, química ou biológica. Está pode ser uma resposta orgânica local ou geral e é desencadeada por diversos fatores que tem como finalidade proteger $o$ indivíduo contra qualquer tipo de agressão. Em determinadas circunstâncias, a resposta é estimulada de tal forma que as reações tornam-se potencialmente destrutivas, alterando as funções e o equilíbrio do organismo. A perda deste controle local ou a aparição de uma resposta hiperativa condiciona uma resposta sistêmica conhecida como sepse. A sepse é caracterizada pela produção excessiva de mediadores inflamatórios e pela excessiva ativação de células inflamatórias que produzem um efeito 
SILVEIRA, S.R., FERREIRA, L.F.L. e LAGE, M.H.H. Fisiopatologia da sepse: revisão de literatura. PUBVET, Londrina, V. 8, N. 9, Ed. 258, Art. 1709, Maio, 2014.

generalizado no organismo. Além dos mediadores inflamatórios também são ativados a cascata de coagulação, a via do ácido araquidônico e a via do óxido nítrico. São esses mediadores que vão ocasionar os sinais clínicos da sepse. A conseqüência desta resposta inflamatória não tratada é uma disfunção orgânica generalizada, que culmina em falha cardiovascular, cerebral e morte do paciente.

Palavras-chave: sepse, inflamação, mediadores inflamatórios

\title{
Pathophysiology of sepsis: literature review
}

\begin{abstract}
Inflammation is a physiological reaction after primary tissue injury, whether physical, chemical or biological. It may be a local or general organic response and is triggered by several factors which aims to protect the individual against any aggression. In certain circumstances, the answer is fostered so that the reactions are potentially destructive, altering the functions and balance of the body. The loss of local control or the appearance of a hyperactive response implies a systemic response known as sepsis. Sepsis is characterized by excessive activation of inflammatory cells and production of inflammatory mediators that produce a widespread effect in the body. Coagulation cascade, route of arachidonic acid and nitric oxide, were also activated. Inflammatory mediators will cause the clinical signs of sepsis. The consequence of this inflammatory response is an untreated widespread organ dysfunction, which culminates in cardiovascular failure, brain and death of the patient.
\end{abstract}

Keywords: sepsis, inflammation, inflammatory mediators 
SILVEIRA, S.R., FERREIRA, L.F.L. e LAGE, M.H.H. Fisiopatologia da sepse: revisão de literatura. PUBVET, Londrina, V. 8, N. 9, Ed. 258, Art. 1709, Maio, 2014.

\section{LISTA DE SIGLAS}

CID - Coagulação intravascular disseminada

ELAM - Molécula de adesão leucócito endotélio

IFN- $\gamma \quad$ - Interferon-Gama

IL $\quad$ - Interleucina

FT $\quad$ - Fator tecidual

FNT- $\alpha \quad$ - Fator de necrose tumoral alfa

GMPc - - Guanosina3 '5'-monofosfato-cíclico

LPS - Lipopolissacarídeo

LPB - Proteína ligadora de LPS

LTA - Ácido lipoteicóico

MHC - Complexo principal de histocompatibilidade

NK - Natural Killer

NO - Óxido nítrico

NOS - Óxido nítrico sintetase

NOSc - Óxido nítrico sintetase constitutivo

NOSe - Óxido nítrico sintetase endotelial

NOSi - Óxido nítrico sintetase induzível

PAF - Fator de agregação plaquetária

PAI-1 - Inibidor do ativador do plasminogênio-1

PGE - Prostaglandina

PMN - Polimorfonuclear

SDMO - Síndrome de disfunção múltipla de órgãos

SIRS - Síndrome da Resposta Inflamatória Sistêmica

TLR - Receptor Toll-like

Th1 - Célula T helper tipo 1

Th2 - Célula T helper tipo 2 
SILVEIRA, S.R., FERREIRA, L.F.L. e LAGE, M.H.H. Fisiopatologia da sepse: revisão de literatura. PUBVET, Londrina, V. 8, N. 9, Ed. 258, Art. 1709, Maio, 2014.

\section{1- INTRODUÇÃO}

Sepse e infecção são termos, freqüentemente, utilizados como independentes, mas isto simplifica uma relação extremamente complexa. Infecção é um processo relacionado à presença de microorganismos. Sepse é o processo relacionado à resposta do hospedeiro à infecção. A distinção entre as duas não é direta, uma vez que infecção, usualmente, envolve algum grau de resposta do hospedeiro. Além do que, esta resposta pode ser mínima ou mesmo ausente em alguns pacientes, como por exemplo, os idosos, os neonatos e os imunossuprimidos. Em muitos casos, na ausência de resposta do hospedeiro, "colonização" poderia ser o termo apropriadamente empregado (SILVA; VICENT, 2010).

Inflamação é a reação fisiológica primária perante agressão tecidual, seja ela de natureza física (mecânica), química ou biológica (bactérias, vírus ou qualquer outro microorganismo vivo). Possui magnitude variável, pode ser uma resposta orgânica local ou geral e é desencadeada por diversos fatores que têm como finalidade proteger o indivíduo contra qualquer tipo de agressão (BONE, 1991).

A inflamação localizada é uma resposta de proteção controlada pelo organismo no local da lesão. No entanto, em determinadas circunstâncias, a resposta é estimulada de tal forma que as reações tornam-se potencialmente destrutivas, alterando as funções e o equilíbrio do organismo. Os compartimentos orgânicos se misturam e as trocas, que se tornam passivas, descaracterizam o que é intra ou extracelular. A perda deste controle local ou a aparição de uma resposta hiperativa condiciona uma resposta sistêmica conhecida como Síndrome da Resposta Inflamatória Sistêmica (SIRS) (SANCHEZ et al., 2004). Para esta circunstância não há tratamento específico e as tentativas de controle se multiplicam em iatrogênias. Razão pela qual grande parte dos pacientes afetados evolui para a morte, o que nos faz supor que a prevenção é o único meio disponível no momento (BONE et al., 1989). 
SILVEIRA, S.R., FERREIRA, L.F.L. e LAGE, M.H.H. Fisiopatologia da sepse: revisão de literatura. PUBVET, Londrina, V. 8, N. 9, Ed. 258, Art. 1709, Maio, 2014.

\section{2- DEFINIÇÃO}

No ano de 1991, na Conferência de Consenso feita pelo American College of Chest Physicians and the Society of Critical Care Medicine, foram estabelecidos critérios para a classificação de sepse e doenças similares (BONE et al., 1992):

Infecção: Fenômeno microbiológico caracterizado por resposta inflamatória à presença de microrganismos ou invasão de um tecido hospedeiro normalmente estéril por estes microrganismos (BONE et al., 1992).

Bacteremia: presença de bactérias viáveis no sangue (BONE et al., 1992).

Síndrome da Resposta Inflamatória Sistêmica (SIRS): conjunto de manifestações clínicas à agressão orgânica grave. A resposta é manifestada por duas ou mais das seguintes condições (valores adaptados para cães e gatos):

(1) temperatura $>39,7^{\circ} \mathrm{C}$ ou $<37,5^{\circ} \mathrm{C}$

(2) freqüência cardíaca > 160 batimentos por minuto para cães e 250 batimentos por minuto para gatos

(3) freqüência respiratória > 20 movimentos respiratórios por minuto ou $\mathrm{PaCO}_{2}$ menor que $32 \mathrm{mmHg}$

(4) contagem de leucócitos $>12.000 / \mathrm{mm}^{3}$ ou $<4.000 / \mathrm{mm}^{3}$, ou mais de $10 \%$ de neutrófilos em banda.

Sepse: situação em que há presença de dois ou mais sinais ou sintomas das condições descritas acima (SIRS) (BONE et al., 1992).

Sepse grave: quadro de sepse associada à disfunção orgânica, hipoperfusão ou hipotensão. Hipoperfusão a perfusão anormais podem incluir, mas não estão limitadas a acidose lática, oligúria ou alteração aguda do estado mental (BONE et al., 1992).

Choque séptico: sepse grave com hipotensão arterial e alteração perfusional persistentes à reposição volêmica adequada. As anormalidades incluem, mas não estão limitadas a acidose lática, oligúria ou alteração aguda do estado mental (BONE et al., 1992). 
SILVEIRA, S.R., FERREIRA, L.F.L. e LAGE, M.H.H. Fisiopatologia da sepse: revisão de literatura. PUBVET, Londrina, V. 8, N. 9, Ed. 258, Art. 1709, Maio, 2014.

Síndrome de disfunção múltipla de órgãos (SDMO): presença ou alteração na função de órgãos num paciente com enfermidade aguda em que a homeostase não possa ser mantida sem intervenção médica (BONE et al., 1992).

A resposta inflamatória sistêmica pode ser desencadeada por fatores infecciosos e não infecciosos (LYNN, 1992). Os eventos fisiopatológicos observados na sepse também são desencadeados por estímulos não infecciosos, como trauma, queimaduras e pancreatite aguda. A expressão síndrome da resposta inflamatória sistêmica (SIRS) é proposta para contemplar todas as situações. Conforme conceitos já expostos, o termo sepse ficaria restrito às alterações desencadeadas por infecções (Figura 1) (BONE et al., 1992).

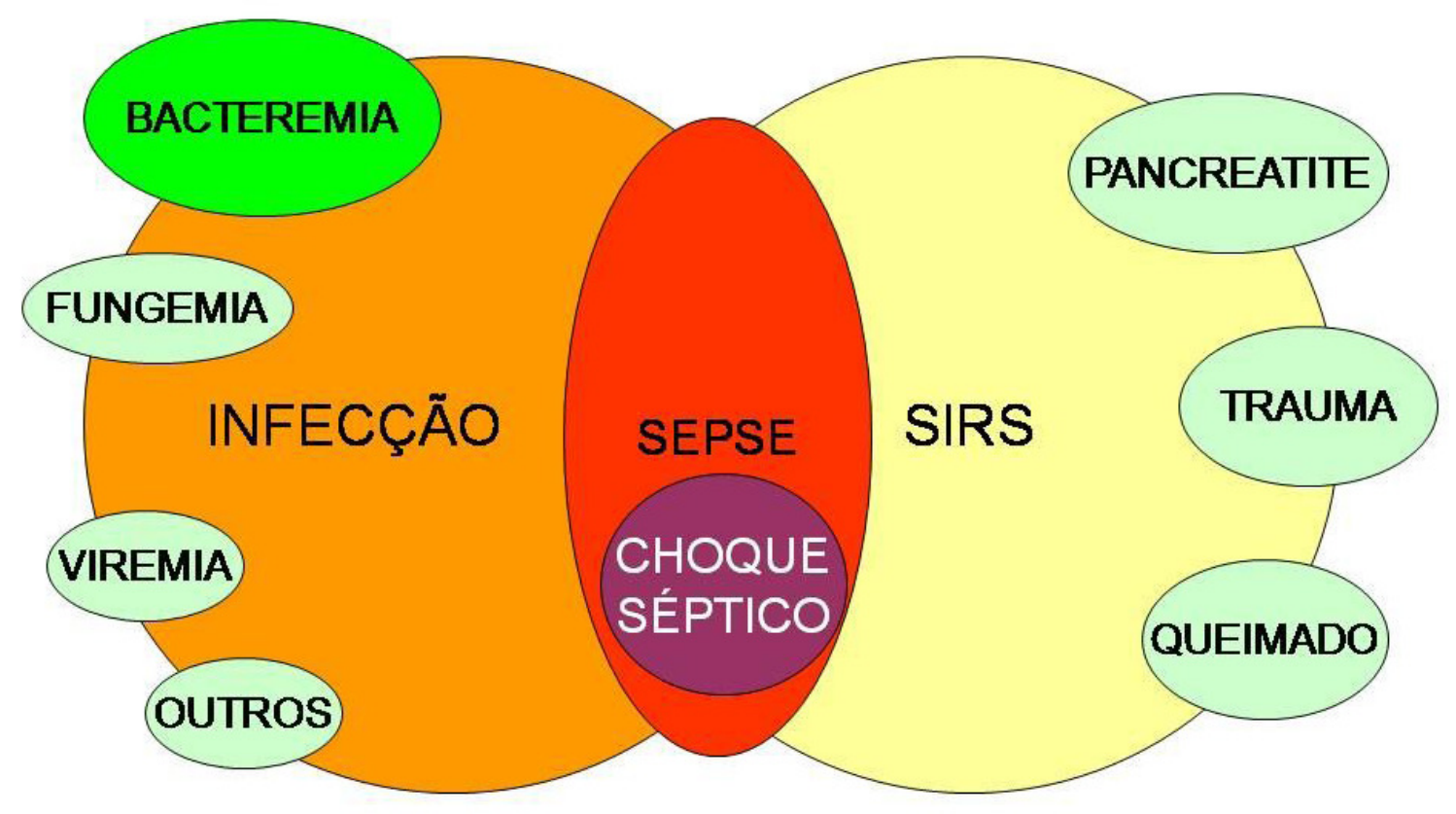

Figura 1: Relação entre Síndrome da Resposta Inflamatória Sistêmica (SIRS), sepse e infecção. Fonte: BONE et al., 1992. 
SILVEIRA, S.R., FERREIRA, L.F.L. e LAGE, M.H.H. Fisiopatologia da sepse: revisão de literatura. PUBVET, Londrina, V. 8, N. 9, Ed. 258, Art. 1709, Maio, 2014.

\section{3- MEDIADORES INFLAMATÓRIOS}

Os mediadores inflamatórios são substâncias endógenas ou exógenas que são libertadas durante a inflamação. Uma vez ativadas desencadeiam, mantêm e ampliam diversos processos envolvidos na resposta inflamatória. Os mediadores exógenos são os peptídeos e os endógenos podem ser divididos em plasmáticos e celulares, conforme demonstrado na figura 2 (PORTH, 2002).

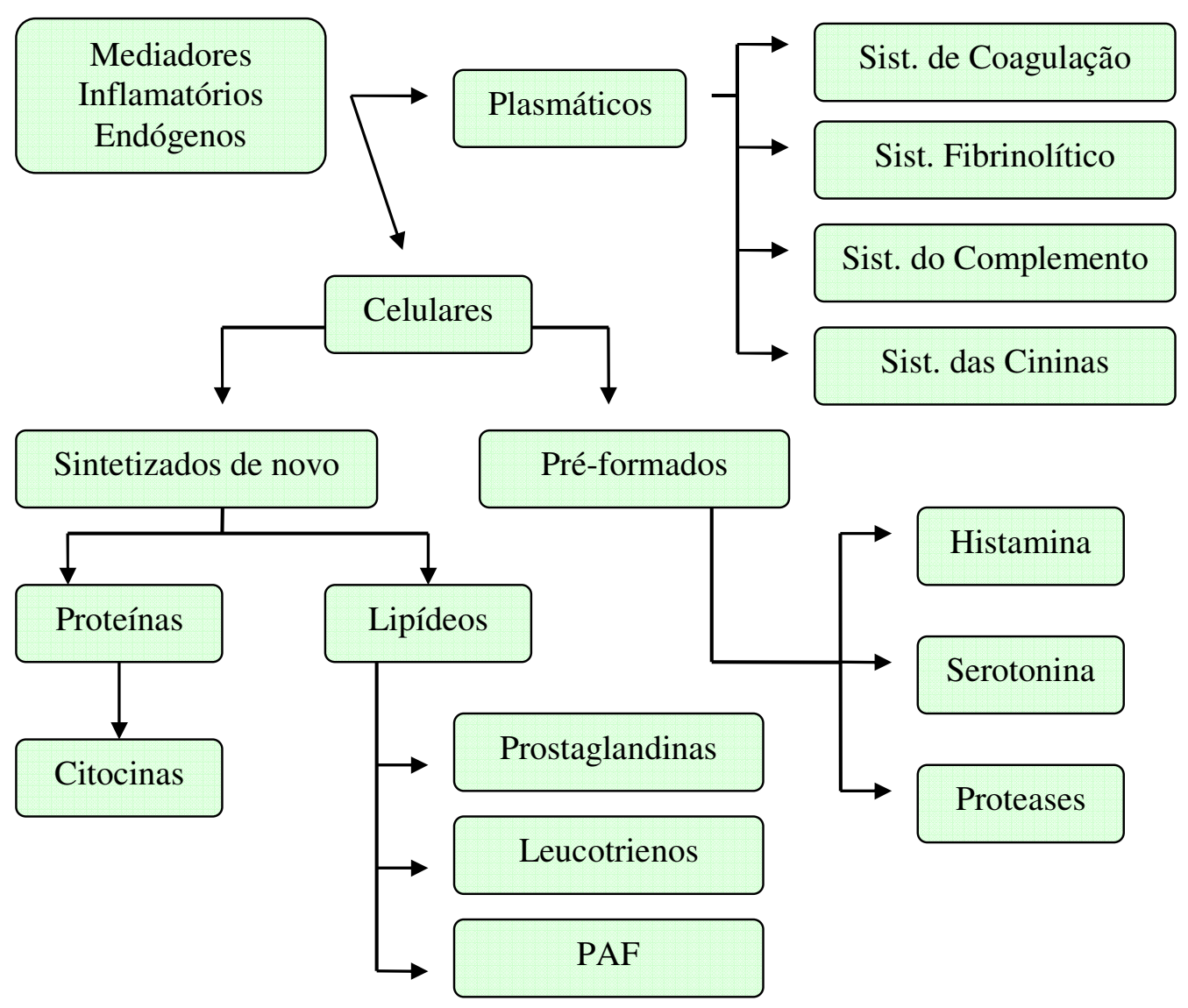

Figura 2: Fluxograma mediadores inflamatórios. 
SILVEIRA, S.R., FERREIRA, L.F.L. e LAGE, M.H.H. Fisiopatologia da sepse: revisão de literatura. PUBVET, Londrina, V. 8, N. 9, Ed. 258, Art. 1709, Maio, 2014.

\subsection{Mediadores Inflamatórios Celulares}

\subsubsection{Sintetizados de novo protéicos}

\subsubsection{Citocinas}

As citocinas constituem um grupo diverso de mediadores peptídicos que se originam de populações de células hospedeiras ativadas. Esses mensageiros celulares são capazes de induzir múltiplas atividades em células hospedeiras locais ou distantes. As citocinas são essenciais para a modulação de processos inflamatórios e imunológicos do hospedeiro (REED, 1998).

As alterações patológicas observadas na sepse são resultado da ação de mediadores endógenos secretados por células inflamatórias ativadas por bactérias e suas toxinas. O papel exercido por diversas citocinas deve ser compreendido dentro do conceito da rede de mediadores da resposta inflamatória. A partir deste princípio, podemos inferir que qualquer uma das citocinas investigadas deverá ter alguma participação na fisiopatologia da sepse e no desenvolvimento do choque séptico. A presença de citocinas nos fluídos biológicos é o resultado de interações complexas entre fatores estimulantes e inibitórios modulando a ação das células através de receptores de superfície de membrana celular. Neste contexto, nenhuma citocina é responsável por si só pelas alterações generalizadas, havendo interdependência de múltiplos mediadores (VERONESI; FOCACCIA, 2001). Acredita-se que o equilíbrio estimulante e inibitório das citocinas que ocorre concomitantemente seja fundamental para uma resposta imune eficaz, que cumpra a função de eliminar o agente infeccioso sem causar danos ao hospedeiro. A alteração desse equilíbrio pode levar a uma resposta imune exacerbada, condição que pode ser deletéria ao organismo (SILVA, 1999).

As citocinas mais estudadas são o FNT- $\alpha$, IL-1 e IL-8, que geralmente são pró-inflamatórias, e IL-6 e IL-10, que tendem a ser antiinflamatória (WHEELER; BERNARD, 1999). 
SILVEIRA, S.R., FERREIRA, L.F.L. e LAGE, M.H.H. Fisiopatologia da sepse: revisão de literatura. PUBVET, Londrina, V. 8, N. 9, Ed. 258, Art. 1709, Maio, 2014.

A seguir descreveremos as citocinas consideradas mais importantes:

\subsection{Fator de Necrose Tumoral Alfa (FNT- $\alpha)$}

O FNT- $\alpha$ é liberado sistemicamente quase que imediatamente após qualquer insulto, modificando a propriedade das células endoteliais, ativando neutrófilos e induzindo a liberação de outras citocinas (WILLIAMS; GIROIR, 1995, PINSKY; TEBOUL, 2005).

É uma citocina com múltiplos efeitos imunológicos e antiinflamatórios. O FNT- $\alpha$ é produzido por macrófagos ativados e outras células, tais como as células B. Esta citocina é um estimulador especialmente potente de IL-1, IL-6 e IL-8. Além de funcionar como principal mediador químico na resposta inflamatória e afetar indiretamente a resposta da febre, o FNT pode atuar como co-estimulador das células T. Na sepse bacteriana, níveis sorológicos elevados de FNT- $\alpha$ podem mediar o choque endotóxico. O FNT- $\alpha$ é principalmente responsável pela degradação dos tecidos observada em casos de inflamação crônica (PORTH, 2005).

\subsection{Interleucina-1 (IL-1)}

A IL-1 é uma citocina polipeptídica importante na mediação de respostas inflamatórias e imunológicas normais do hospedeiro (REED, 1998). A maior parte da IL-1 produzida durante a sepse deriva de macrófagos e monócitos em resposta a LPS, FNT- $\alpha$, ou leucotrienos (VERONESI; FOCACCIA, 2001, PORTH, 2005, REED, 1998). Porém, também pode ser produzida pelos ceratinócitos, células de Langerhans, células B normais, células $T$ cultivadas, fibroblastos, neutrófilos e células musculares lisas (PORTH, 2005).

A IL-1 é considerada uma citocina pró-inflamatória por apresentar propriedades pró-inflamatórias semelhantes ao $\mathrm{FNT}-\alpha$, sendo que a produção 
SILVEIRA, S.R., FERREIRA, L.F.L. e LAGE, M.H.H. Fisiopatologia da sepse: revisão de literatura. PUBVET, Londrina, V. 8, N. 9, Ed. 258, Art. 1709, Maio, 2014.

de IL-1 é estimulada pelo FNT- $\alpha$ e a IL-1, por sua vez, potencializa muito dos efeitos do FNT- $\alpha$ (DAL NOGARE, 1991).

A IL-1 possui efeitos pleiotrópicos, exercendo ação hormonal em praticamente todos os tecidos e órgãos. Seu papel é fundamental na indução e regulação da resposta inflamatória, tanto local quanto sistêmica (VERONESI; FOCACCIA, 2001).

Juntamente com a IL-6 e FNT- $\alpha$, a IL-1 é capaz de estimular a produção de uma resposta da fase aguda, mobilizar neutrófilos, produzir febre e ativar o epitélio vascular, além de participar da ativação de fosfolipase, no catabolismo muscular, em alterações hematológicas, na ativação linfocitária e em desarranjos endoteliais (REED, 1998, PORTH, 2005).

A IL-1 pode servir como sinal para iniciar a ativação de células T CD4, bem como o crescimento e diferenciação das células B (PORTH, 2005).

\subsection{Interleucina-6 (IL-6)}

A IL-6 é uma citocina polipeptídica que participa em muitos aspectos da função imunológica e antiinflamatória do hospedeiro. Muitas células são capazes de produzir IL-6, incluindo monócitos, macrófagos, células endoteliais e fibroblastos (REED, 1998).

A secreção de IL-6 é estimulada pela IL-1 e FNT- $\alpha$, suas principais ações na sepse são de modulação da inflamação sistêmica e da resposta de fase aguda. Acredita-se que esta citocina estimula os hepatócitos a produzirem proteínas de fase aguda que, provavelmente, sejam moduladoras da resposta inflamatória com função predominantemente inibidora, ou seja, funcionariam com retroalimentação negativa dentro da rede de mediadores da inflamação. Em conjunto com a IL-2 e IL-4 estimula e ativa linfócitos $B$, aumentando a produção de anticorpos, também estimula linfócitos T citotóxicos, monócitos e PMN. Níveis plasmáticos de IL-6 podem ser observados durante a evolução do choque séptico, com boa correlação com a letalidade (VERONESI; FOCACCIA, 2001). 
SILVEIRA, S.R., FERREIRA, L.F.L. e LAGE, M.H.H. Fisiopatologia da sepse: revisão de literatura. PUBVET, Londrina, V. 8, N. 9, Ed. 258, Art. 1709, Maio, 2014.

\subsection{Interleucina-8 (IL-8)}

A IL-8 é produzida por macrófagos no local da inflamação, sendo um potente quimioatratvo para fagócitos ativados por IL-1 ou FNT- $\alpha$. A secreção de IL-8 é dependente da presença de outras citocinas, principalmente do FNT$\alpha$. Durante a sepse ou choque séptico pode-se detectar níveis plasmáticos elevados correlacionando-se com a letalidade (VERONESI; FOCACCIA, 2001).

A IL-8 induz a liberação de enzimas, que aumentam a produção de superóxidos, regulando para mais as moléculas de adesão e aumentando a migração transendotelial. Além deste efeito também exerce atividade quimiotáxica sobre os linfócitos (BELLOMO, 1992).

\subsection{Interleucina $10(\mathrm{IL}-10)$}

A IL-10 é uma citocina produzida por macrófagos, linfócitos T CD4+ e também por linfócitos T CD8+ e linfócitos B. Um de seus principais efeitos é a supressão da ativação antígeno-específica da célula $T$ e da função de apresentação de antígenos pelos monócitos, macrófagos, células de Langerhans e células dendríticas. A IL-10 também inibe a ativação da célula T por meio da supressão direta da produção de IL-2 e INF- $\gamma$ pelo linfócito. Outras citocinas inflamatórias como IL-1, IL-6, e FNT- $\alpha$ também tem sua produção in vitro inibida pela IL-10 (MOSMANN, 1994).

A IL-10 é produzida por meio de vários estímulos, incluindo-se LPS e bactérias Gram-positivas e Gram-negativas mortas (VAN DER POLL, 1994).

\subsection{Interferon-Gama (IFN- $\gamma$ )}

Existem três tipos de IFN: IFN- $\alpha$, produzido pelos neutrófilos, IFN- $\beta$, produzido por fibroblastos e IFN- $\gamma$ produzido pelas células T CD4+ e CD8+ ativados e por células natural killer (FARRAR; SCHREIBER, 1993). Os IFN- $\alpha$ e IFN- $\beta$ atuam contra diferentes tipos de vírus e parasitas intracelulares. Os IFN 
SILVEIRA, S.R., FERREIRA, L.F.L. e LAGE, M.H.H. Fisiopatologia da sepse: revisão de literatura. PUBVET, Londrina, V. 8, N. 9, Ed. 258, Art. 1709, Maio, 2014.

produzidos durante as reações imunológicas da sepse são principalmente IFN- $\gamma$ (PORTH, 2005).

O IFN- $\gamma$ tem função central na resposta imune celular, agindo como ativador de macrófagos, promotor da diferenciação de linfócitos $T$ gerando linfócitos citotóxicos, ativador de neutrófilos e estimulador da atividade das células NK (FARRAR; SCHREIBER, 1993, PORTH, 2005).

O FNT- $\alpha$ estimula a produção de IFN- $\gamma$ por linfócitos NK, independente da presença de células T ou B. O efeito sinergético obtido pela interação desta citocina é de fundamental importância no desenvolvimento da resposta de defesa de primeira linha contra a invasão bacteriana. A produção de IFN- $\gamma$ por linfócitos NK seria um dos fatores essenciais para desencadear a resposta de fase aguda pelos macrófagos (VERONESI; FOCACCIA, 2001).

\subsubsection{Sintetizados de novo lipídicos}

\subsubsection{Eucosanóides}

Os eucosanóides são um grupo de mediadores lipídicos que incluem prostaglandinas, tombaxanos e leucotrienos. Os eucosanóides são produzidos a partir de muitas células, incluindo neutrófilos, macrófagos, células endoteliais vasculares, plaquetas e células de músculo liso. Esses mediadores são operantes em processos inflamatórios locais e generalizados (REED, 1998).

A lesão da membrana de vários tipos de células levam a ativação do metabolismo do ácido araquidônico. Através da fosfolipase $A_{2}$, o ácido araquidônico, um ácido graxo, é liberado pelos fosfolipídeos da membrana celular (PORTH, 2005). A partir do ácido araquidônico dois grupos de substâncias vasoativas são produzidos: prostaglandinas pela via metabólica da ciclooxigenase, e os leucotrienos pela via da lipooxigenase (Figura 3) (VERONESI; FOCACCIA, 2001). 
SILVEIRA, S.R., FERREIRA, L.F.L. e LAGE, M.H.H. Fisiopatologia da sepse: revisão de literatura. PUBVET, Londrina, V. 8, N. 9, Ed. 258, Art. 1709, Maio, 2014.

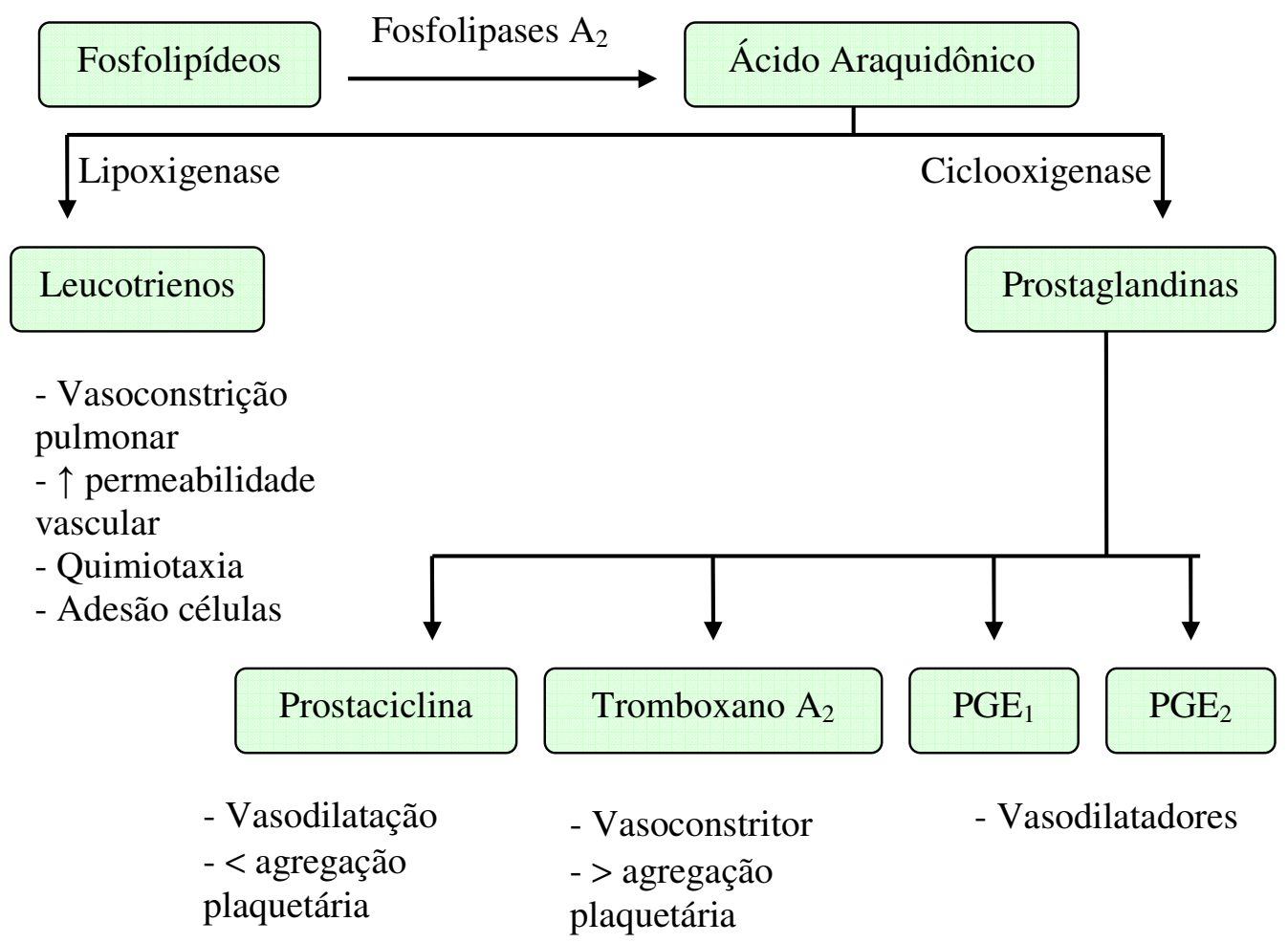

Figura 3: Fluxograma eucosanóides.

O troboxano $\mathrm{A}_{2}$ é produzido nas plaquetas e leva à vasoconstrição, agregação de plaquetas e broncoconstrição, contribuindo para as alterações iniciais hemodinâmicas e na microvascularização induzidas por endotoxina que causam isquemia tecidual (REED, 1998, VERONESI; FOCACCIA, 2001, PORTH, 2005). As prostaglandinas contribuem com a vasodilatação, permeabilidade capilar, bem como dor e febre que acompanham a inflamação (PORTH, 2005). As prostaglandinas estáveis $\left(\mathrm{PGE}_{1} \quad \mathrm{e} \quad \mathrm{PGE}_{2}\right)$ induzem à inflamação e potencializam os efeitos da histamina e outros mediadores inflamatórios (PORTH, 2005). A PGE 1 tem efeito vasodilatador e supressor da resposta inflamatória, antagonizando os efeitos vasoconstritores do tromboxano (VERONESI; FOCACCIA, 2001). Dentre as diversas prostaglandinas, tem fundamental importância a prostaciclina, que causa vasodilatação e aumento da permeabilidade capilar, além de desfavorecer a agregação plaquetária. A 
SILVEIRA, S.R., FERREIRA, L.F.L. e LAGE, M.H.H. Fisiopatologia da sepse: revisão de literatura. PUBVET, Londrina, V. 8, N. 9, Ed. 258, Art. 1709, Maio, 2014.

ação vasodilatadora das prostaglandinas se dá ao nível das pequenas arteríolas e contrabalança os efeitos de mediadores vasoconstritores. (VERONESI; FOCACCIA, 2001).

Os leucotrienos consistem nos mediadores químicos primeiramente descobertos nos leucócitos. Como as prostaglandinas, são formadas do ácido araquidônico, porém através da via da lipooxigenase. A histamina e os leucotrienos são complementares em sua ação e possuem funções similares. A histamina é produzida rápida e transitoriamente, enquanto os leucotrienos mais potentes estão sendo sintetizados. Os leucotrienos são descritos como capazes de afetar a permeabilidade das vênulas pós-capilares, as propriedades de adesão das células endoteliais bem como a quimiotaxia e extravascularização dos neutrófilos, eosinófilos e monócitos (PORTH, 2005). Estes mediadores estão envolvidos na redução do débito cardíaco e da função renal que ocorre na endotoxemia. Nos pulmões produzem vasoconstrição e broncoconstrição potente e prolongada (VERONESI; FOCACCIA, 2001). Os hormônios glicocorticóides ou drogas reduzem a disponibilidade do ácido araquidônico necessário à síntese das prostaglandinas (PORTH, 2005).

\subsubsection{Fator ativador de plaquetas (PAF)}

É um metabólito gerado de um complexo lipídico armazenado nas membranas celulares, o PAF afeta uma variedade de tipos celulares e induz à agregação plaquetária. Ativa os neutrófilos e exerce um efeito quimiotático potente dos eosinófilos (PORTH, 2005).

O PAF atua em processos fisiológicos normais bem como em processos inflamatórios (REED, 1998). É liberado pelos macrófagos, leucócitos, PMN, plaquetas e células endoteliais. Este mediador inflamatório fosfolipídico aumenta a adesão celular e ativa as células endoteliais por efeito direto ou através da formação de radicais tóxicos de oxigênio ou metabólitos do ácido araquidônico (SALLES et al, 1999). 
SILVEIRA, S.R., FERREIRA, L.F.L. e LAGE, M.H.H. Fisiopatologia da sepse: revisão de literatura. PUBVET, Londrina, V. 8, N. 9, Ed. 258, Art. 1709, Maio, 2014.

O PAF além de ativar PMN e plaquetas, estimula a liberação de proteases, prostaglandinas e leucotrienos, contribuindo de maneira efetiva no estabelecimento de lesões tissulares. O FNT- $\alpha$ amplifica os efeitos do PAF, que por sua vez age sinergeticamente para induzir a produção de mais FNT- $\alpha$ (VERONESI; FOCACCIA, 2001).

\subsubsection{Pré-formados}

\subsubsection{Histamina:}

A histamina é um dos primeiros mediadores da resposta inflamatória sendo encontrada em alta concentração nas plaquetas, basófilos e mastócitos (PORTH, 2002). Provoca dilatação e aumento da permeabilidade dos capilares venosos (CRUVINEL et al, 2009).

\subsubsection{Serotonina:}

A serotonina é liberada das plaquetas que se agregam durante o processo de coagulação. Provoca vasoconstrição e participa de modo importante no controle da hemorragia (PORTH, 2002).

\subsubsection{Proteases do Plasma:}

As quininas são complementos protéicos ativados e fatores da coagulação (CRUVINEl et al, 2009). A bradiquinina provoca o aumento da permeabilidade capilar e dor (PORTH, 2002). 
SILVEIRA, S.R., FERREIRA, L.F.L. e LAGE, M.H.H. Fisiopatologia da sepse: revisão de literatura. PUBVET, Londrina, V. 8, N. 9, Ed. 258, Art. 1709, Maio, 2014.

\section{2- Mediadores Inflamatórios Plasmáticos}

\subsection{1- Sistema de Coagulação}

A coagulação sanguínea é o processo pelo qual as fibras de fibrina formam uma rede que retém os componentes sanguíneos juntos. O sistema de coagulação pode ser ativado através de duas vias, a via intrínseca e a via extrínseca. A via intrínseca é um processo mais lento e começa no próprio sangue e a via extrínseca é um processo mais rápido que se inicia com o traumatismo do vaso sanguíneo ou dos tecidos circundantes (PORTH, 2002; FRANCO, 2001). Essas duas vias convergem para a ativação do fator $\mathrm{X}$ e a formação de fibrina induzida pela trombina que é o material que estabiliza o coágulo (CARLOS; FREITAS, 2007).

O sistema intrínseco é ativado quando o sangue entra em contato com o colágeno na parede vascular lesada e o sistema extrínseco é ativado quando o sangue é exposto a extratos teciduais (FRANCO, 2001).

O processo de coagulação é controlado por numerosas substâncias que promovem a coagulação (fatores pró-coagulantes) ou a inibem (fatores anticoagulantes) (PORTH, 2002). A ação de um fator da coagulação destina-se a ativar o fator seguinte na seqüência (CARLOS; FREITAS, 2007).

Os fatores da coagulação podem ser divididos em três grupos. O primeiro grupo compõe-se de fibrinogênio (fator I) e dos fatores V, VIII e XIII, sendo que o fator XIII estabiliza a fibrina e os outros atuam como substrato para trombina. Os fatores $\mathrm{V}$ e VIII atuam como cofatores que aceleram o processo de coagulação. No segundo grupo, que é vitamina $K$ dependente, inclui os fatores II, VII, IX, X e as proteínas C e S. Já o terceiro grupo inclui os fatores XI, XII (Figura 4) (CARLOS; FREITAS, 2007; FRANCO, 2001). 
SILVEIRA, S.R., FERREIRA, L.F.L. e LAGE, M.H.H. Fisiopatologia da sepse: revisão de literatura. PUBVET, Londrina, V. 8, N. 9, Ed. 258, Art. 1709, Maio, 2014.

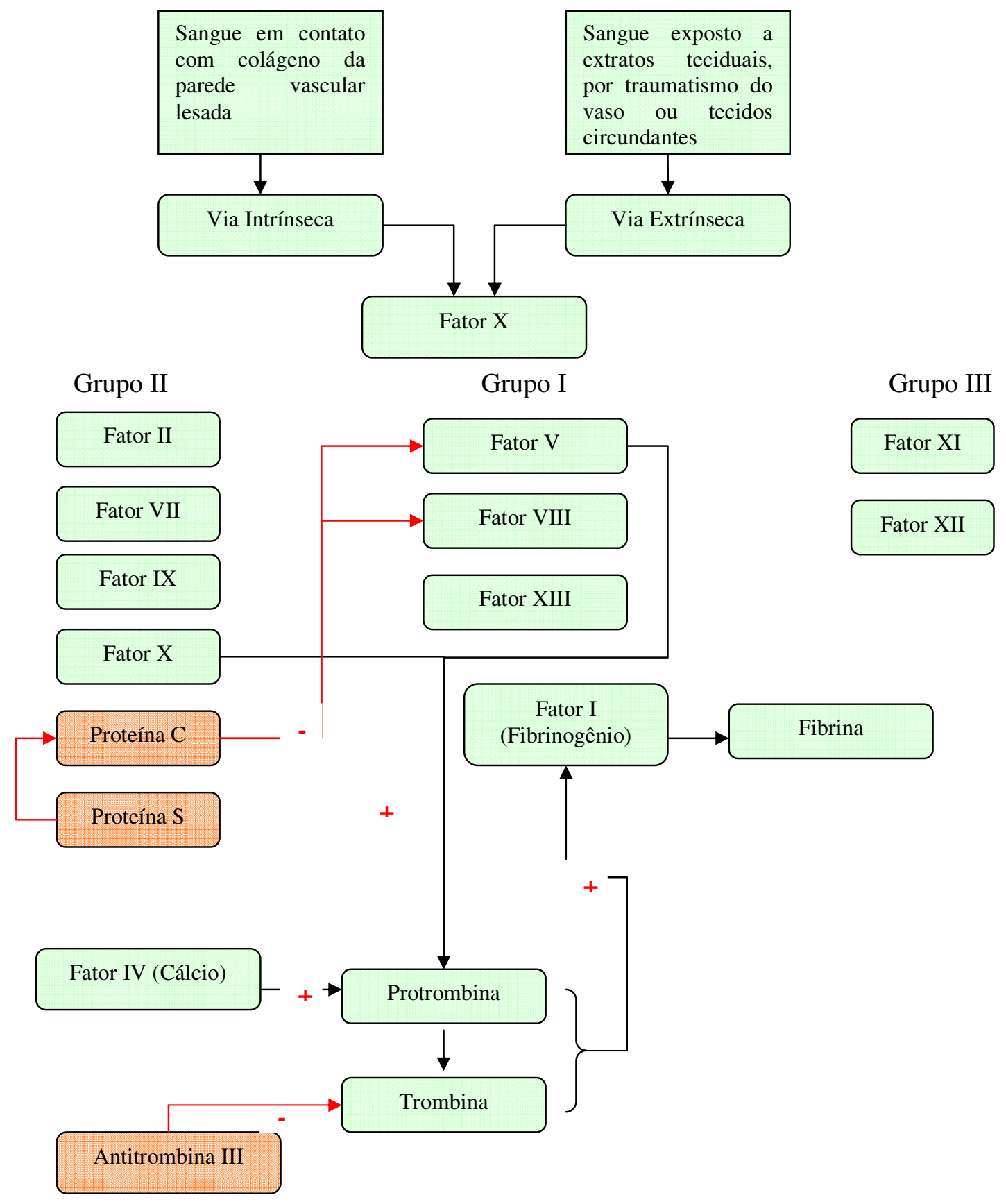

Figura 4: Fluxograma sistema coagulação.

O cálcio (fator IV) é necessário na maioria das etapas do processo de coagulação. A inativação dos íons cálcio impede a coagulação do sangue (PORTH, 2002). O cálcio, os fatores $X$ e $V$ combinam-se para formar o ativador 
SILVEIRA, S.R., FERREIRA, L.F.L. e LAGE, M.H.H. Fisiopatologia da sepse: revisão de literatura. PUBVET, Londrina, V. 8, N. 9, Ed. 258, Art. 1709, Maio, 2014.

da protrombina que, em seguida, converte a protrombina em trombina. Essa interação provoca a conversão de fibrinogênio nos filamentos de fibrina (LEHNE, 1998).

A coagulação é regulada por vários anticoagulantes naturais. A antitrombina III inativa os fatores da coagulação e neutraliza a trombina, a última enzima da via para a conversão de fibrinogênio em fibrina (TAKAHIRA, 2006). A proteína C, uma proteína plasmática, atua como anticoagulante inativando os fatores V e VIII (TAKAHIRA, 2006; PORTH, 2002). A proteína S, outra proteína plasmática acelera a ação da proteína C (PORTH, 2002; FRANCO, 2001). A plasmina decompõe a fibrina em produtos de degradação da fibrina, que atuam como anticoagulantes (GARCIA-NAVARRO, 2005).

Além da inflamação, os microorganismos também ativam a cascata da coagulação, com aumento dos fatores pró-coagulantes e redução dos anticoagulantes. A cascata da coagulação é composta de uma série de reações em cadeia. Essas reações ocorrem nas membranas ativadas de fosfolipídeos e em alguns casos são aceleradas pela presença de cofatores, como o fator VIIIa e Va. Para cada resposta pró-coagulante existe uma reação anticoagulante natural (HENKIN et al, 2009).

A ativação da cascata de coagulação na sepse é conseqüência da ação do LPS e do FNT- $\alpha$ sobre o endotélio, ativando a via extrínseca por indução do fator tissular na superfície de monócitos ativados e em tecido subendotelial exposto ao sangue circulante. A via intrínseca é ativada em seguida à ativação da via extrínseca, e seu papel é mais restrito a indução de hipotensão através da ativação do sistema das cininas. A atividade pró-coagulante gerada pelo FNT- $\alpha$ contribui através da inibição da fibrinólise, redução dos níveis plasmáticos de proteína $\mathrm{S}$ e aumento do inibidor do ativador do plasminogênio do tipo I (PAI-1), levando a maior deposição intravascular de fibrina o que caracteriza o estado de coagulação intravascular disseminada (LEVI; CATE; POLL, 1993). 
SILVEIRA, S.R., FERREIRA, L.F.L. e LAGE, M.H.H. Fisiopatologia da sepse: revisão de literatura. PUBVET, Londrina, V. 8, N. 9, Ed. 258, Art. 1709, Maio, 2014.

\subsubsection{Sistema Fibrinolítico}

O sistema fibrinolítico é formando pelo plasminogênio e todas as moléculas que o convergem em plasmina. Tem como função dissolver o coágulo de fibrina (CARLOS; FREITAS, 2007).

A plasmina digere as fibras de fibrina do coágulo e determinados fatores da coagulação, como o fibrinogênio, o fator V, o fator VII, a protrombina e o fator XII (PORTH, 2002).

A fibrina é dissolvida em vários fragmentos chamados de produtos de degradação da fibrina que tem ação anticoagulante, interferem na função plaquetária e também atuam sobre a inibição da trombina. A lesão vascular é recuperada por fibroblastos estimulados que migram para a área lesada e produzem colágeno para reparo vascular permanente. Fatores e crescimento plaquetário, estimulam a formação de novas células endoteliais e colágeno, estimulando a produção de fibroblastos para reparar a área lesada (FRANCO, 2001; CARLOS; FREITAS, 2007).

A ativação do sistema fibrinolítico ocorre em pacientes sépticos com coagulação vascular disseminada, com uma redução nos níveis plasmáticos de proteínas fibrinolíticas e aumento de produtos de degradação de fibrinogênio. A ativação fibrinolítica é interpretada como um processo secundário pela ativação da coagulação. O sistema fibrinolítico inicialmente é ativado e posteriormente inibido (GEORGE; SHATTIL, 1991).

Após o aumento do nível da atividade fibrinolítica, há um aumento nos níveis do inibidor do ativador do plasminogênio (PAI-1), com completa inibição da atividade fibrinolítica. Uma vez que a atividade fibrinolítica é máxima, ocorre um desequilíbrio do sistema procoagulante e fibrinolítico. Este seria o responsável pela incompleta dissolução dos depósitos de fibrina na microcirculação de pacientes sépticos (VOSS et al., 1990).

A proteína $C$ tem um importante papel na regulação da trombose e fibrinólise pela inibição não somente dos fatores de coagulação $V$ e VIII, mas 
SILVEIRA, S.R., FERREIRA, L.F.L. e LAGE, M.H.H. Fisiopatologia da sepse: revisão de literatura. PUBVET, Londrina, V. 8, N. 9, Ed. 258, Art. 1709, Maio, 2014.

também do PAI-1, portanto, a proteína C ativada tem atividade anticoagulante e profibrinolítica na CID induzida pela sepse (VOSS et al., 1990).

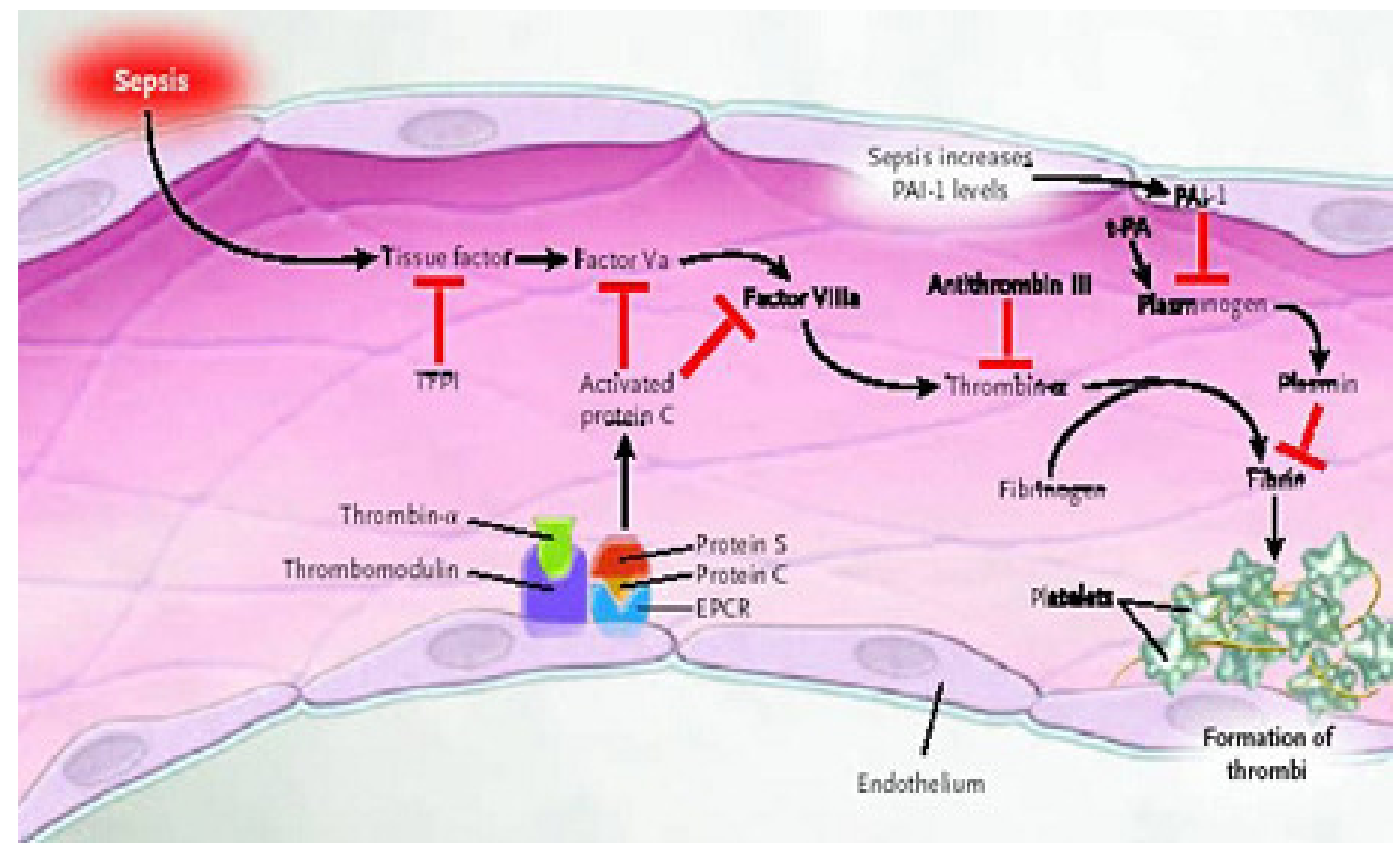

Figura 5: Ativação da coagulação na sepse. As células endoteliais e a ativação de células mononucleares podem produzir citocinas pró-inflamatórias que vão induzir a ativação da coagulação. A ativação da coagulação é iniciada pela expressão do fator tecidual. Além disso, a regulação dos mecanismos fisiológicos anticoagulantes e inibição da fibrinólise mediada por PAI-1 promovem a deposição de fibrina intravascular. Fonte: RUSSEL, 2006.

\subsubsection{Sistema do Complemento}

O sistema do complemento é formado por uma grande quantidade de proteínas plasmáticas diferentes que reagem entre elas para opsonizar os patógenos e induzir uma série de respostas inflamatórias que ajudam a combater a infecção (UTIYAMA; REASON; KOTZE, 2004). Essas proteínas atuam em uma reação sequencial em cascata e representam um dos principais mediadores da defesa inata do hospedeiro e da inflamação (JANEWAY et al., 2002). 
SILVEIRA, S.R., FERREIRA, L.F.L. e LAGE, M.H.H. Fisiopatologia da sepse: revisão de literatura. PUBVET, Londrina, V. 8, N. 9, Ed. 258, Art. 1709, Maio, 2014.

Existem três maneiras pelas quais o sistema complemento protege contra a infecção (UTIYAMA; REASON; KOTZE, 2004). Primeiro, produz um grande número de proteínas do complemento ativadas que se unem covalentemente ao patógeno, opsonizando-o para englobamento por parte de fagócitos com receptores para o complemento. Segundo, os pequenos fragmentos de algumas proteínas do complemento atuam como quimioatraentes para recrutar mais fagócitos ao sítio da ativação do complemento, ativando esses fagócitos. Terceiro, os componentes terminais do complemento causam dano em certas bactérias, criando poros na membrana bacteriana (JANEWAY et al., 2002). Outro aspecto muito importante da ativação do sistema do complemento é a viabilização de fatores que propiciam a remoção e/ou eventual dissolução de imunocomplexos (complexos antígeno: anticorpo), formados em decorrência da presença de antígenos solúveis presentes em processos infecciosos (MACHADO et al., 2004).

A ativação do sistema complemento ocorre através de diferentes mecanismos ou vias de ativação: via clássica, que é ativada por patógenos ou através da interação de anticorpos com antígeno; e as vias alternativa e das lectinas que podem ser desencadeadas diretamente por alguns tipos de antígeno. (ITURRY-YAMAMOTO; PORTINHO, 2001; SILVA et al., 2003). Nessas vias, através da ativação de certos componentes, enzimas são geradas, resultando em uma reação amplificada (ITURRY-YAMAMOTO; PORTINHO, 2001).

A via clássica é iniciada pela ligação de $\mathrm{C} 1 \mathrm{q}$, a primeira proteína da cascata do complemento, diretamente à superfície do patógeno ou através da ligação de C1q aos complexos antígeno: anticorpo (JANEWAY et al., 2002). A via da lectina é iniciada pela ligação de uma lectina sérica ligadora de manose, a carboidratos contendo manose em bactérias ou vírus (ABBAS; LICHTMAN; PILLAI, 2007). Finalmente a via alternativa pode ser iniciada quando um componente espontaneamente ativado do complemento se liga a superfície de um patógeno (JANEWAY et al., 2002). Cada via segue uma seqüência de 
SILVEIRA, S.R., FERREIRA, L.F.L. e LAGE, M.H.H. Fisiopatologia da sepse: revisão de literatura. PUBVET, Londrina, V. 8, N. 9, Ed. 258, Art. 1709, Maio, 2014.

reações para gerar uma protease denominada convertase C3 (Figura 6) (ITURRY-YAMAMOTO; PORTINHO, 2001).

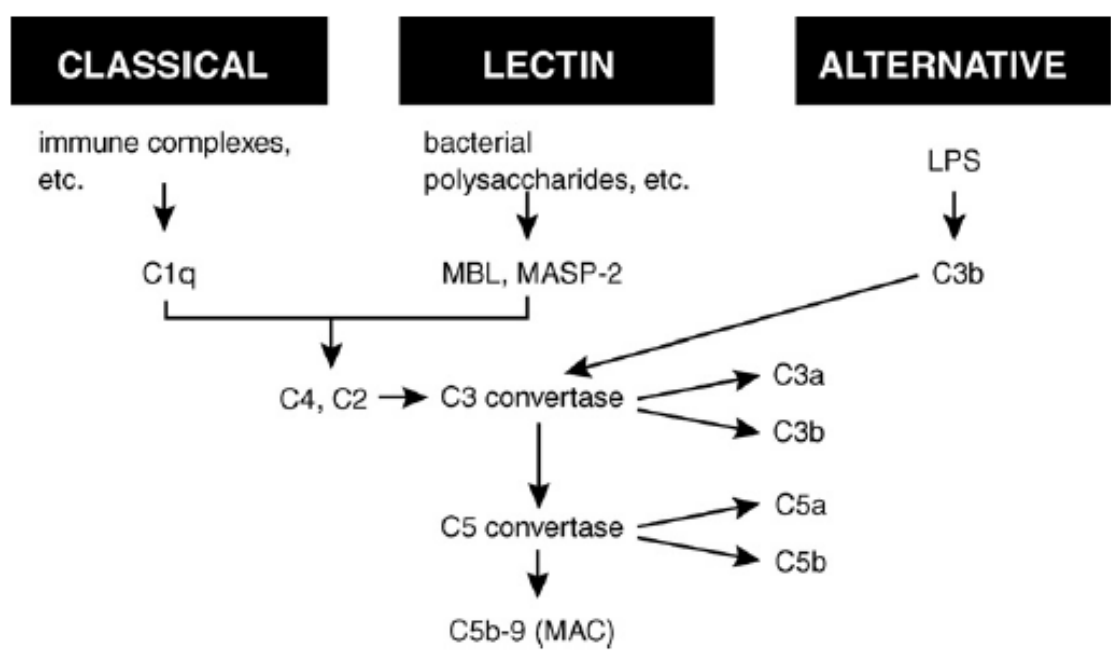

Figura 6: As três vias de ativação do complemento que resultam em produtos biologicamente ativos de C3 e C5. Fonte: WARD, 2008.

As convertases C3 se unem covalentemente à superfície do patógeno onde clivam o C3 para produzir o componente ativo do sistema complemento C3b (ABBAS; LICHTMAN; PILLAI, 2007). A ligação de grande número de moléculas de $\mathrm{C} 3 \mathrm{~b}$ ao patógeno sinalizam para a destruição pelos fagócitos portadores de receptores para C3b (ABBAS; LICHTMAN; PILLAI, 2007; JANEWAY et al, 2002).

Os fragmentos pequenos de clivagem do C3, C4 e especialmente C5 recrutam fagócitos aos sítios de infecção e ativam-nos pela ligação a receptores específicos acoplados a proteína G. Juntas, essas atividades promovem a capacitação e a destruição dos patógenos por fagócitos (ABBAS; LICHTMAN; PILLAI, 2007).

As moléculas de C3b que se ligam à C3 convertase iniciam os eventos tardios, com a ligação ao C5 tornando-o suscetível à clivagem por C2b. O C5a 
SILVEIRA, S.R., FERREIRA, L.F.L. e LAGE, M.H.H. Fisiopatologia da sepse: revisão de literatura. PUBVET, Londrina, V. 8, N. 9, Ed. 258, Art. 1709, Maio, 2014.

é o mediador mais importante da inflamação e o C5b desencadeia formação do complexo de ataque à membrana que cria um poro nas membranas celulares de alguns patógenos levando à sua morte (JANEWAY et al., 2002).

Em pacientes com sepse são encontrados níveis altos de C3a, e há correlação entre estes níveis e a gravidade e letalidade do quadro clínico. Animais com deficiência de C5a não desenvolvem choque após o desafio com FNT- $\alpha$ e LPS. Além disso, C3a e C5a são potentes anafilotoxinas, e podem induzir secreção de citocinas como IL-1, IL-6 e FNT- $\alpha$, agindo sinergicamente para produzir aumento da permeabilidade capilar e hipotensão (VERONESI; FOCACCIA, 2001; BEUTLER; POLTORAK, 2001).

Como a atividade do complemento é baseada na atividade de várias enzimas, a presença de componentes reguladores que impedem a lesão tecidual devido à ligação inadvertida de componentes ativados do complemento às células do hospedeiro ou da ativação espontânea dos componentes do complemento no plasma é bastante importante. É exatamente devido à ação de alguns destes fatores que a reação em cadeia pode ser efetuada na membrana de determinadas células "alvo", não se desencadeando sobre as membranas das células do próprio hospedeiro (SILVA; VICENT, 2003).

\subsubsection{Sistema das Cininas}

A bradicinina é liberada na circulação via ativação do calicreinogênio para calicreína, pelo fator XII e pela lesão endotelial. O bradicininogênio é catalisado pela calicreína em bradicinina (VERONESI; FOCACCIA, 2001). A bradicinina exerce uma potente ação vasodilatadora e de aumento da permeabilidade capilar (CRUVINEL et al, 2009). 
SILVEIRA, S.R., FERREIRA, L.F.L. e LAGE, M.H.H. Fisiopatologia da sepse: revisão de literatura. PUBVET, Londrina, V. 8, N. 9, Ed. 258, Art. 1709, Maio, 2014.

\section{4- ÓXIDO NÍTRICO}

O óxido nítrico (NO) é uma molécula gasosa, altamente hidrofóbica e facilmente difusível através de membranas biológicas. É sintetizado a partir de oxigênio molecular e do aminoácido L-arginina por um grupo de enzimas conhecidas como óxido nítrico sintetase (NOS) (VINCENT et al, 2000). O NO tem papel fundamental no controle fisiológico do tônus vascular (BATLOUNI; RAMIRES,1994).

Nas últimas décadas, tornou-se evidente que, na patogênese da sepse, o NO pode atuar de maneira deletéria ou benéfica, em nível celular e vascular (VICENT et al, 2000 e HAUSER et al, 2005). Embora conhecidas as suas propriedades vasodilatadoras, seu efeitos pró- e antiinflamatórios, bem como oxidantes e antioxidantes, entre outro, tem sido motivo de discussões e controvérsias (HAUSER et al, 2005).

A NOS apresenta-se em três isoformas no organismo (Figura 7), que pode ser:

1) cálcio-dependente: isoforma constitutiva (NOSc) que é dividida em neuronais (NOSn ou NOS-1) e endoteliais (NOSe ou NOS-3) (HAUSER et al, 2005, VICENT et al, 2000).

2) cálcio-independente: isoforma induzível (NOSi ou NOS-2) (HAUSER et al, 2005, VICENT et al, 2000).

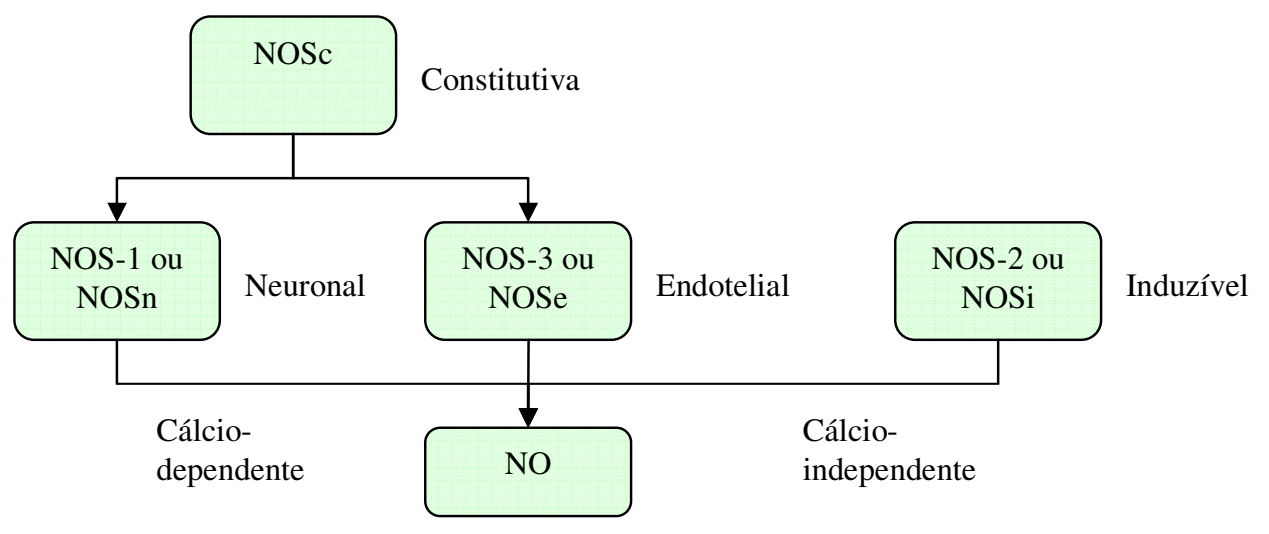

Figura 7: Fluxograma óxido nítrico. 
SILVEIRA, S.R., FERREIRA, L.F.L. e LAGE, M.H.H. Fisiopatologia da sepse: revisão de literatura. PUBVET, Londrina, V. 8, N. 9, Ed. 258, Art. 1709, Maio, 2014.

O NO derivado da NOSn (NOS-1) atua como um neurotransmissor e está presente no rim, músculo esquelético, miocárdio, e pâncreas. Já o NO derivado da NOSe (NOS-3) desempenha um papel importante na regulação do tônus vascular e fluxo sanguíneo regional e também está presente em algumas células imunológicas (HAUSER et al, 2005).

A NOSi (NOS-2) é expressa em células do sistema imunológico, eritrócitos, músculo liso vascular, rins, pâncreas, fígado e pulmão (HAUSER et al, 2005). A atividade da NOSi é induzida quando certas células são ativadas por agentes pró-inflamatórios, como as endotoxinas, FNT- $\alpha$, ITF- $\gamma$ e IL-1. Além destes, outros agentes também estão bem determinados como importantes na produção da NOSi, tais como a IL-2 e PAF, produzindo NO por tempo prolongado (KNOBEL, 1996).

A indução da NOSi ocorre através da calmodulina, após induzida, ocorre produção de NO (desde que a disponibilidade da L-arginina seja suficiente) (VICENT et al, 2000), em maiores quantidades e por tempo mais prolongado e constante do que o NO produzido de uma forma fisiológica sob efeito da NOSc (KNOBEL, 1996).

A liberação de NO através da NOSc exerce um efeito protetor no choque séptico. Como ocorrem elevadas concentrações de diversas substâncias vasoconstritoras, o NO atua melhorando o tônus vascular, prevenindo, por tanto, uma vasoconstrição periférica excessiva e diminuição do fluxo (KNOBEL, 1996).

A sepse grave é freqüentemente associada a uma alteração no balanço entre o oxigênio disponível e seu consumo, com uma redução na extração de oxigênio pelos tecidos associada à alteração importante na regulação da microcirculação (AKAMINE et al, 1994).

Existem evidências de que o choque séptico é caracterizado por uma resposta deprimida ou diminuída a agentes vasopressores, evidenciado por uma baixa resistência vascular periférica, que, do ponto de vista hemodinâmico, contribui para a vasodilatação periférica acentuada (AKAMINE et al, 1994, SALLES et al, 1999). Este fenômeno não está totalmente 
SILVEIRA, S.R., FERREIRA, L.F.L. e LAGE, M.H.H. Fisiopatologia da sepse: revisão de literatura. PUBVET, Londrina, V. 8, N. 9, Ed. 258, Art. 1709, Maio, 2014.

esclarecido, mas provavelmente alguns mecanismos participam na resposta diminuída aos agentes vasopressores, tais como: o aumento da formação de metabólitos do ácido araquidônico, uma redução nos receptores alfa adrenérgicos e diminuição na disponibilidade de cálcio nos elementos contráteis, além de outras não bem elucidadas (KNOBEL, 1996).

O NO também pode reagir com ânion superóxido para formar peroxinitrito, um processo oxidante com efeitos tóxicos sobre muitas células, incluindo os ácidos nucléicos, lipídios e proteínas. O peroxinitrito também compromete a respiração mitocondrial e ativa a enzima poli-ADP ribose sintetase, diminuindo a taxa de glicólise, transporte de elétrons e geração de ATP (VICENT et al, 2000).

\subsection{Efeitos sobre a função miocárdica}

No processo séptico evidencia-se uma depressão miocárdica que é causada por vários fatores depressores do miocárdio, tais como as interleucinas 2 e 6 , o FNT- $\alpha$ e, atualmente, sabe-se que o NO exerce um papel fundamental na etiopatogenia desta depressão miocárdica (KNOBEL, 1996).

O NO pode se ligar ao grupo heme contendo proteínas como a guanilatociclase, que ativa a liberação de guanosina3' 5 '-monofosfato-cíclico (cGMP). As ações mediadas pelo cGMP incluem o relaxamento do músculo liso e do miocárdio e inibição da agregação plaquetária (VICENT et al, 2000), vasodilatação e modulação da adesão de leucócitos, contribuindo para a diminuição do retorno venoso e disfunção do miocárdio (SALLES et al, 1999). Os efeitos inotrópicos negativos são, provavelmente, mediados por cGMP, bem como pelo comprometimento da auto-regulação coronária e utilização de oxigênio (VICENT, 2000).

No coração a NOSc e a NOSi são encontradas no endocárdio, no endotélio vascular e nos miócitos. Acumulam-se evidências sugerindo que o NO pode ser o principal mediador da depressão miocárdica na sepse. Foi 
SILVEIRA, S.R., FERREIRA, L.F.L. e LAGE, M.H.H. Fisiopatologia da sepse: revisão de literatura. PUBVET, Londrina, V. 8, N. 9, Ed. 258, Art. 1709, Maio, 2014.

também demonstrado que a perfusão miocárdica está aumentada no processo séptico e que o NO é um coronariodilatador (KNOBEL, 1996)

Vários estudos vêm demonstrando contradições em relação ao papel do NO, demonstrando nenhum efeito do NO ou de inibidores da NOS sobre o miocárdio e receptores adrenérgicos beta. Algumas dessas inconsistências podem ser relacionadas com as diferenças entre espécies de animais utilizadas ou na preparação experimental, a dose de inibidor de NOS, a dose de endotoxina, o tipo de tecido analisado, o tempo de tratamento, a colheita, ou a presença de cálcio no meio de incubação antes do experimento. No entanto, na maioria dos estudos, doses baixas a moderadas de inibidores e NOSi restauram a contratilidade miocárdica em corações expostos a citocinas próinflamatórias, enquanto que em doses mais elevadas, o efeito inverte-se. Esse achado pode indicar que pequenas quantidades de NO produzido pela NOSi pode ser necessário para manter a contratilidade (VICENT et al, 2000).

Sabe-se que, fisiologicamente, o fluxo pulsátil na circulação sistêmica é um fator produtor de NO. Esse fato é mais evidente nas artérias onde a quantidade de NO produzido é maior do que nas veias. Deste modo, quando há um aumento no fluxo pulsátil, a liberação de NO é mais acelerada. Na circulação coronária, o NO também desempenha um papel importante na adaptação do fluxo coronário que pode aumentar inúmeras vezes durante um esforço físico (KNOBEL, 1996).

\subsection{Efeitos sobre a circulação pulmonar}

O efeito da NOS na lesão pulmonar aguda é controverso, já que tem sido descritos tanto efeitos negativos quanto positivos (HAUSER et al, 2005).

$\mathrm{Na}$ sepse, um desequilíbrio entre NO (vasodilatador) e os fortes vasoconstritores endotelinas e tromboxano resultam em vasoconstrição pulmonar e hipertensão pulmonar (VICENT et al, 2000). Do ponto de vista fisiopatológico, na reação do NO com outros radicais livres o peroxinitrito é produzido, sob influência de mediadores da inflamação, e pode ter um efeito 
SILVEIRA, S.R., FERREIRA, L.F.L. e LAGE, M.H.H. Fisiopatologia da sepse: revisão de literatura. PUBVET, Londrina, V. 8, N. 9, Ed. 258, Art. 1709, Maio, 2014.

nocivo no tecido pulmonar nestas situações. Outros efeitos não oxidantes do NO também podem participar na lesão pulmonar aguda. Porém não há comprovação se a produção aumentada do NO no comprometimento inflamatório dos pulmões pode ser maléfica ou benéfica (KNOBEL, 1996).

\subsection{Efeitos sobre o trato gastrointestinal}

O trato gastrintestinal é um dos primeiros a sofrer conseqüências nas situações em que ocorre redução do fluxo sanguíneo ou em decorrência de processo séptico. No intestino existe produção de NO em alguns tecidos, como no epitélio, na musculatura lisa, no plexo neural e nos mastócitos (KNOBEL, 1996).

Em condições normais, a perfusão da mucosa é regulada pelo NO produzido no endotélio vascular da região mesentérica. Além desta regulação da circulação, o NO participa do peristaltismo e da ação dos esfíncteres. Fisiologicamente, o NO mantém uma perfusão adequada no intestino, inibindo a adesão de neutrófilos no endotélio, bloqueando a adesão de plaquetas e prevenindo a ativação de macrófagos (KNOBEL, 1996).

Nas condições inflamatórias existe liberação de NOSi, com conseqüente produção de NO em excesso, ocorrendo lesão e hiperemia da mucosa e quebra da barreira, propiciando a translocação bacteriana. Desta forma, o processo séptico pode se iniciar ou perpetuar-se (KNOBEL, 1996).

\section{5- FISIOPATOLOGIA DA SEPSE}

A sepse pode ser definida como uma síndrome clínica resultante de uma complexa interação entre o hospedeiro e o agente infeccioso. É caracterizada pela ativação sistêmica da resposta inflamatória envolvendo citocinas, mediadores de fase aguda e proteínas da coagulação. Sua patogenia está associada a modificações hemodinâmicas, distúrbios da microcirculação e alterações celulares que levam a um desequilíbrio entre o fluxo sanguíneo e os 
SILVEIRA, S.R., FERREIRA, L.F.L. e LAGE, M.H.H. Fisiopatologia da sepse: revisão de literatura. PUBVET, Londrina, V. 8, N. 9, Ed. 258, Art. 1709, Maio, 2014.

requerimentos metabólicos tissulares acarretando a disfunção de múltiplos órgãos, responsável pela forma agressiva e geralmente fatal da sepse (WHEELER; BERNARD, 1999).

Normalmente, uma potente e complexa cascata imunológica garante uma resposta imediata de proteção à invasão microbiana. Apesar de algumas incertezas, pode ser construído em esquema razoável dos eventos bioquímicos do início da sepse (WHEELER; BERNARD, 1999).

Muitos mediadores e tipos celulares estão envolvidos na inflamação. A interação entre mediador inflamatório e seu receptor celular permite uma variedade de respostas celulares dependentes das diferentes concentrações de mediadores. Esta interação resulta em uma comunicação intercelular extremamente sensível. As interações entre receptor-mediador inflamatório regulam os vários níveis de modulação da resposta inflamatória, aumentando ou diminuindo a produção de mediadores inflamatórios, regulando para mais ou para menos os seus receptores e produzindo receptores agonistas e antagonistas. Outra característica importante deste sistema é a redundância, ou seja, múltiplos mediadores com funções que se sobrepõem são gerados durante a resposta inflamatória aguda. Por sua vez, mediadores específicos alteram a resposta celular quando interagem com diferentes citocinas, permitindo desta maneira modular a resposta inflamatória dependendo do tecido específico (SILVA; FRIEDMAN, 1999).

A inflamação é, essencialmente, uma resposta adaptativa do organismo à agressão, numa tentativa de promover a cicatrização e a cura, aumentando sua capacidade de luta inclusive contra infecção. Seguindo-se à agressão, o hospedeiro é exposto imediatamente a um número de substâncias próinflamatórias derivada tanto de fontes endógenas como exógenas, sendo a bactéria a fonte exógena mais freqüente (WILLIANS; GIROIR, 1995).

Numa concepção atual, a sepse pode ser descrita em três estágios: os estágios I e II representam a fase inicial da resposta inflamatória (PURVIS; KIRB, 1994). 
SILVEIRA, S.R., FERREIRA, L.F.L. e LAGE, M.H.H. Fisiopatologia da sepse: revisão de literatura. PUBVET, Londrina, V. 8, N. 9, Ed. 258, Art. 1709, Maio, 2014.

\section{1- Estágio I}

A primeira fase é exclusivamente local, mediada pela produção inicial de citocinas (PURVIS; KIRB, 1994). A resposta imune inata é responsável pelo processo inflamatório inicial da sepse (HENKIN et al, 2009). A reação inflamatória é desencadeada pelo estímulo de componentes dos microrganismos a algumas células do sistema imune (Figura 1). Os principais componentes são o ácido lipoteicóico (LTA) e peptideoglicanos, derivados de bactérias gram-positivas, e o lipopolissacrídeo (LPS), no caso de bactérias gram-negativas (endotoxinas). As toxinas bacterianas são liberadas quando ocorre um evento de lise da parede celular, como na replicação e na morte celular da bactéria (OPAL, 2007).

Os receptores TLR-2 reconhecem os peptídeoglicanos das bactérias gram positivas, enquanto que os receptores TLR-4 reconhecem os lipopolissacerídeos das gram negativas (HENKIN et al, 2009).

O principal receptor para LPS presente na membrana das células fagocitárias é o TLR-4, da família dos receptores Toll-like. O reconhecimento do LPS pelo TRL-4 depende de moléculas acessórias como a proteína ligadora de LPS (LPB) (JEAN-BAPTISTE, 2007). A formação do complexo LPS/LPB facilita a ligação do LPS ao seu receptor CD14 na superfície do monócito, desencadeando assim a transdução do sinal com a ativação do fator de transcrição Nf KappaB e consequente produção de citocinas e outros mediadores inflamatórios (Figura 8 e 9) (WRIGHT; RAMOS; TOBIAS, 1990).

A interação com outros alvos do hospedeiro, como as células endoteliais que não expressam CD14 na superfície é mediado por molécula de CD14 solúvel, que então liga-se ao complexo LPS-LBP e interage com outra molécula de superfície celular ainda não conhecida (SRISKANDAN; COHEN, 1995). Existem evidências bastante fortes sugerindo que a molécula receptora de LPS seja o CD14, cuja maior expressão se dá na superfície de monócitos e macrófagos (VERONESI; FOCCACIA, 2001). 
SILVEIRA, S.R., FERREIRA, L.F.L. e LAGE, M.H.H. Fisiopatologia da sepse: revisão de literatura. PUBVET, Londrina, V. 8, N. 9, Ed. 258, Art. 1709, Maio, 2014.

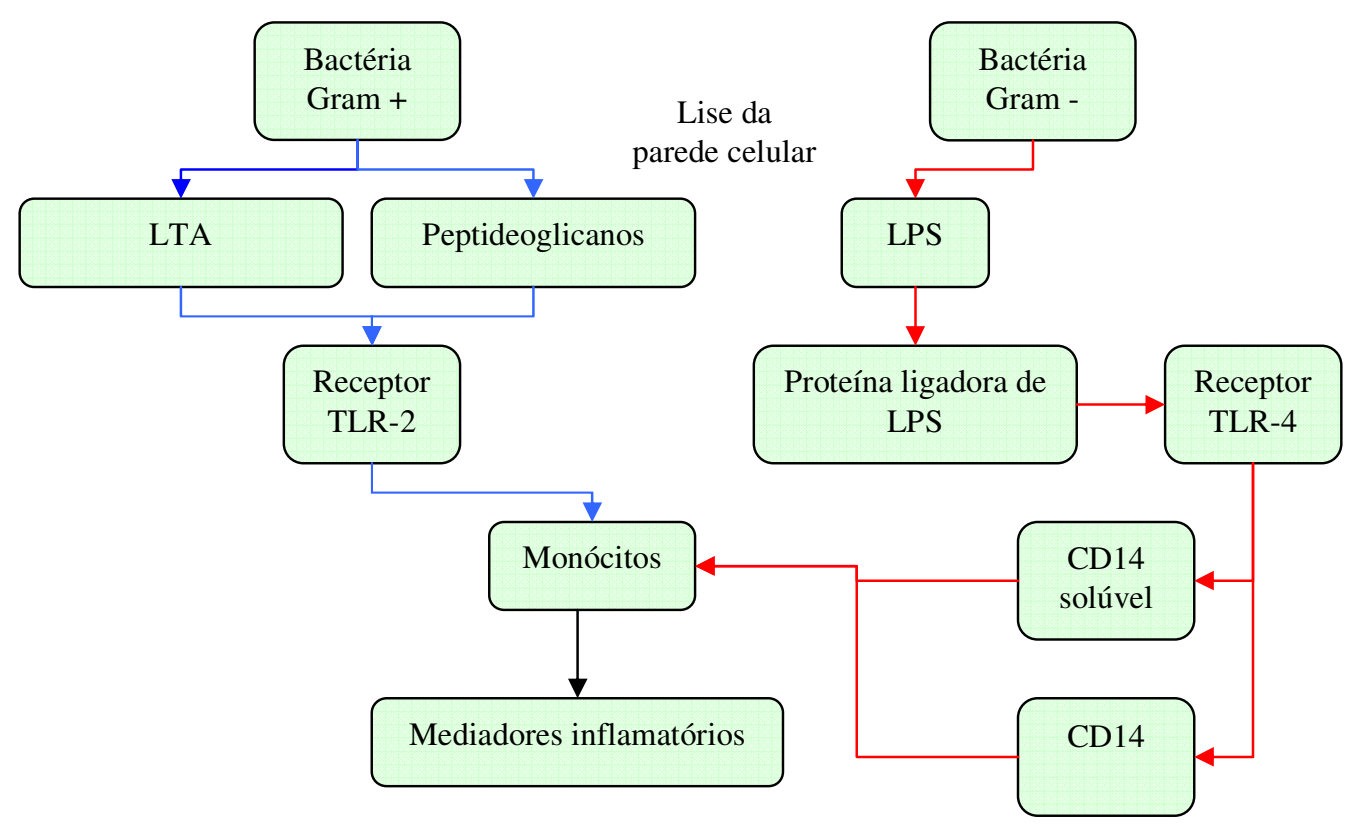

Figura 8: Fluxograma estágio I. 
SILVEIRA, S.R., FERREIRA, L.F.L. e LAGE, M.H.H. Fisiopatologia da sepse: revisão de literatura. PUBVET, Londrina, V. 8, N. 9, Ed. 258, Art. 1709, Maio, 2014.

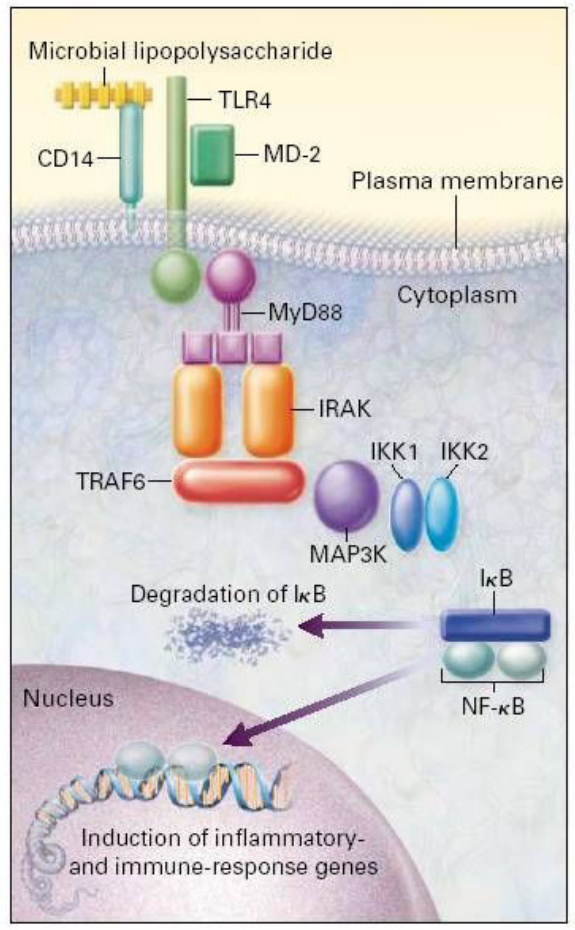

Figura 9: Estágio I da fisiopatologia da sepse. O LPS é liberado a partir da bactéria durante lise bacteriana por fagócitos. Em seguida ocorre a interação do LPS com o receptor CD14 que fornece a transdução de sinal desencadeando os eventos subseqüentes. Fonte: RUSSEL, 2006.

\section{2- Estágio II}

Uma vez ativados, os TLRs desencadeiam uma cascata de eventos intracelulares que culmina com a translocação nuclear do NF-kB, um fator de transcrição que promove a expressão gênica de moléculas pró-inflamatórias, como FNT-a e IL-1 e também citocinas anti-inflamatórias como IL-10 (HENKIN et al, 2009).

As células mononucleares ativas por endotoxinas liberam mediadores de peptídeos (citocinas), mais notavelmente FNT- $\alpha$, IL-1 e IL-6. A endotoxina desencadeia atividade monocítica da fosfolipase $A_{2}$ e da fosfolipase $C$ que resulta na produção de mediadores do ácido araquidônico (eucosanóides) e do PAF. Através da liberação inicial desses mediadores peptídicos e lipídicos, os 
SILVEIRA, S.R., FERREIRA, L.F.L. e LAGE, M.H.H. Fisiopatologia da sepse: revisão de literatura. PUBVET, Londrina, V. 8, N. 9, Ed. 258, Art. 1709, Maio, 2014.

monócitos ativam leucócitos, células endoteliais e plaquetas do hospedeiro (Figura 10) (REED, 1998).

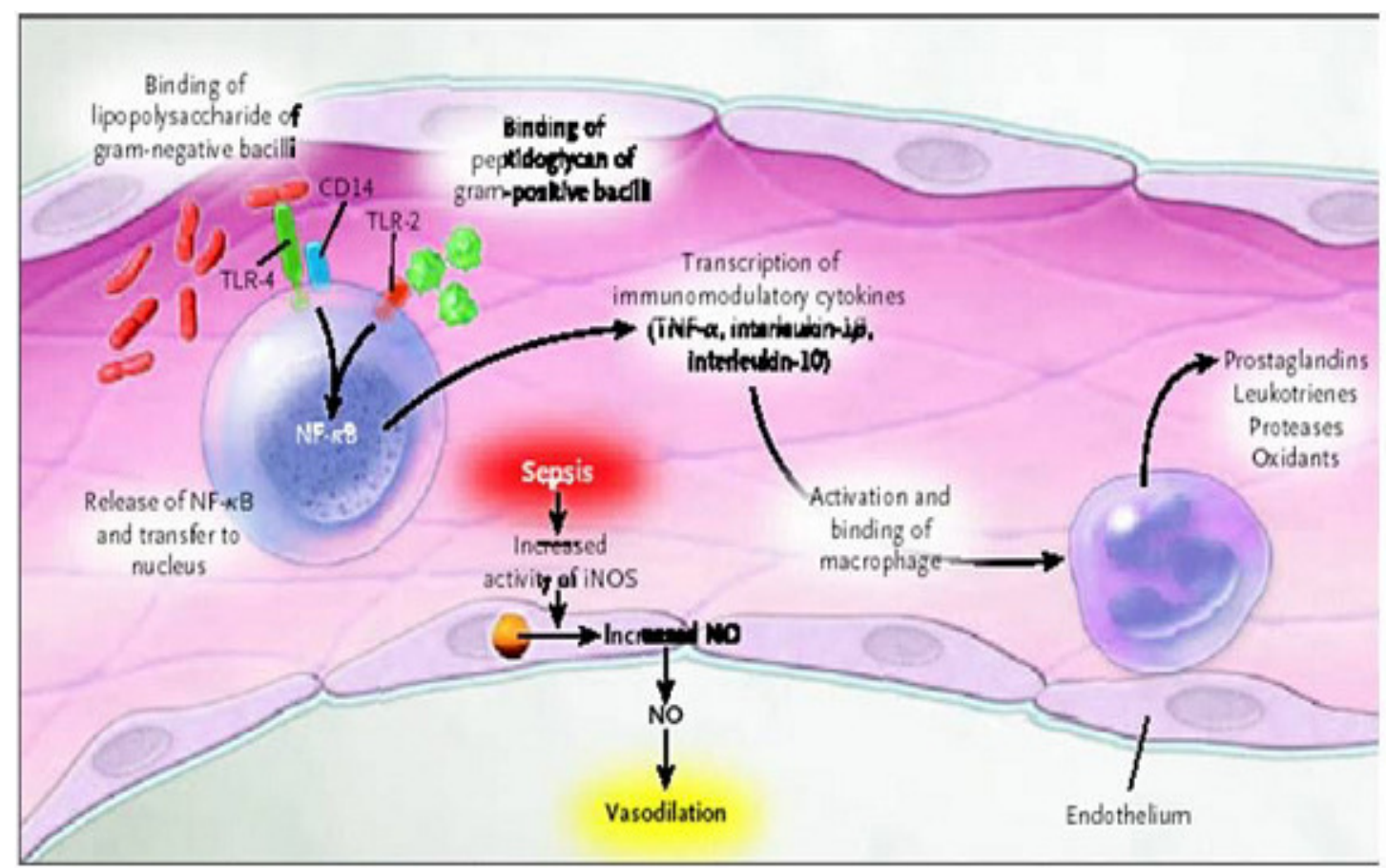

Figura 10: Resposta inflamatória na sepse e seus efeitos hemodinâmicos. Fonte: RUSSEL, 2006.

Os eventos celulares são iniciados, em grande parte, pelo macrófago, que exerce o processamento e a apresentação do antígeno para o linfócito T. $\mathrm{O}$ contato célula-célula, por meio do complexo principal de histocompatibilidade (MHC-II) e do receptor de célula $T$, ativa a célula $\mathrm{CD} 4+$, ainda com a participação de citocinas como o FNT- $\alpha$ e IL-1, produzidas pelo macrófago. A célula CD4+ ativada produz IL-2 e INF- $\gamma$ que iniciam a ativação de novas células CD4+, além de CD8+, células Natural Killer e os próprios macrófagos. O macrófago ativado reinicia a produção de FNT- $\alpha$, que atua ativando células CD4+ e novos macrófagos. Na presença de FNT- $\alpha$ ocorre aumento da expressão de receptores de IL-2 e INF- $\gamma$, potencializando a ativação de linfócitos. Por outro lado, o INF- $\gamma$ é potente ativador do macrófago, expressando ainda mais MHC-II e produzindo nova carga de FNT- $\alpha$. Essa série 
SILVEIRA, S.R., FERREIRA, L.F.L. e LAGE, M.H.H. Fisiopatologia da sepse: revisão de literatura. PUBVET, Londrina, V. 8, N. 9, Ed. 258, Art. 1709, Maio, 2014.

de eventos mostra como a célula $\mathrm{CD} 4+$ e o macrófago atuam amplificando a resposta imune celular, usando como ferramentas as citocinas FNT- $\alpha$, IL-2 e INF- $\gamma$ (SILVA; FRIEDMAN, 1999).

O FNT-a e IL-1 ativam a resposta imune adaptativa que é responsável pela amplificação da imunidade inata. Esta caracteriza-se pela ativação das células B que liberam imunoglobulinas facilitadoras da apresentação de antígenos para as células fagocitárias. Além disso, as células $\mathrm{T}$ helper tipo 1 (Th1) promovem um feedback positivo, secretando citocinas pró-inflamatórias (FNT-a e IL-1). Contrabalançando esse mecanismo, as células T helper tipo 2 (Th2) secretam interleucinas anti-inflamatórias (IL-4, IL-10) (HENKIN et al, 2009). O equilíbrio entre os tipos de resposta Th1 (celular, inflamatório) e Th2 (humoral, antiinflamatório) da célula CD4+ ativada é considerado fundamental para o controle da agressão infecciosa. O predomínio de um tipo de resposta em relação ao outro pode resultar em imunidade ineficaz e provocar o processo infecção/doença (SILVA; FRIEDMAN, 1999).

A célula CD4+ sintetiza ainda, quando ativada, as citocinas IL-4 e IL-5, que atuam diferenciando e ativando as células $B$, exercendo assim um estímulo para a resposta imune humoral. Por outro lado, juntamente com a IL-10, atua inibindo a resposta imune celular (REED, 1998).

As citocinas pró-inflamatórias aumentam a expressão de moléculas de adesão em leucócitos e células endoteliais. Embora os neutrófilos ativados destruam microorganismos, eles também causam aumento da permeabilidade vascular, ocasionando edema tecidual. Além disso, as células endoteliais ativadas liberam óxido nítrico, um potente vasodilatador que tem papel fundamental na patogênese do choque séptico. A ativação dos monócitos e macrófagos e a intensa ação dos mediadores iniciais acarretam a síntese de outras citocinas, como IL-6, IL-8 e IL-10, com vários efeitos sinérgicos e antagônicos na resposta inflamatória (HENKIN et al, 2009). 
SILVEIRA, S.R., FERREIRA, L.F.L. e LAGE, M.H.H. Fisiopatologia da sepse: revisão de literatura. PUBVET, Londrina, V. 8, N. 9, Ed. 258, Art. 1709, Maio, 2014.

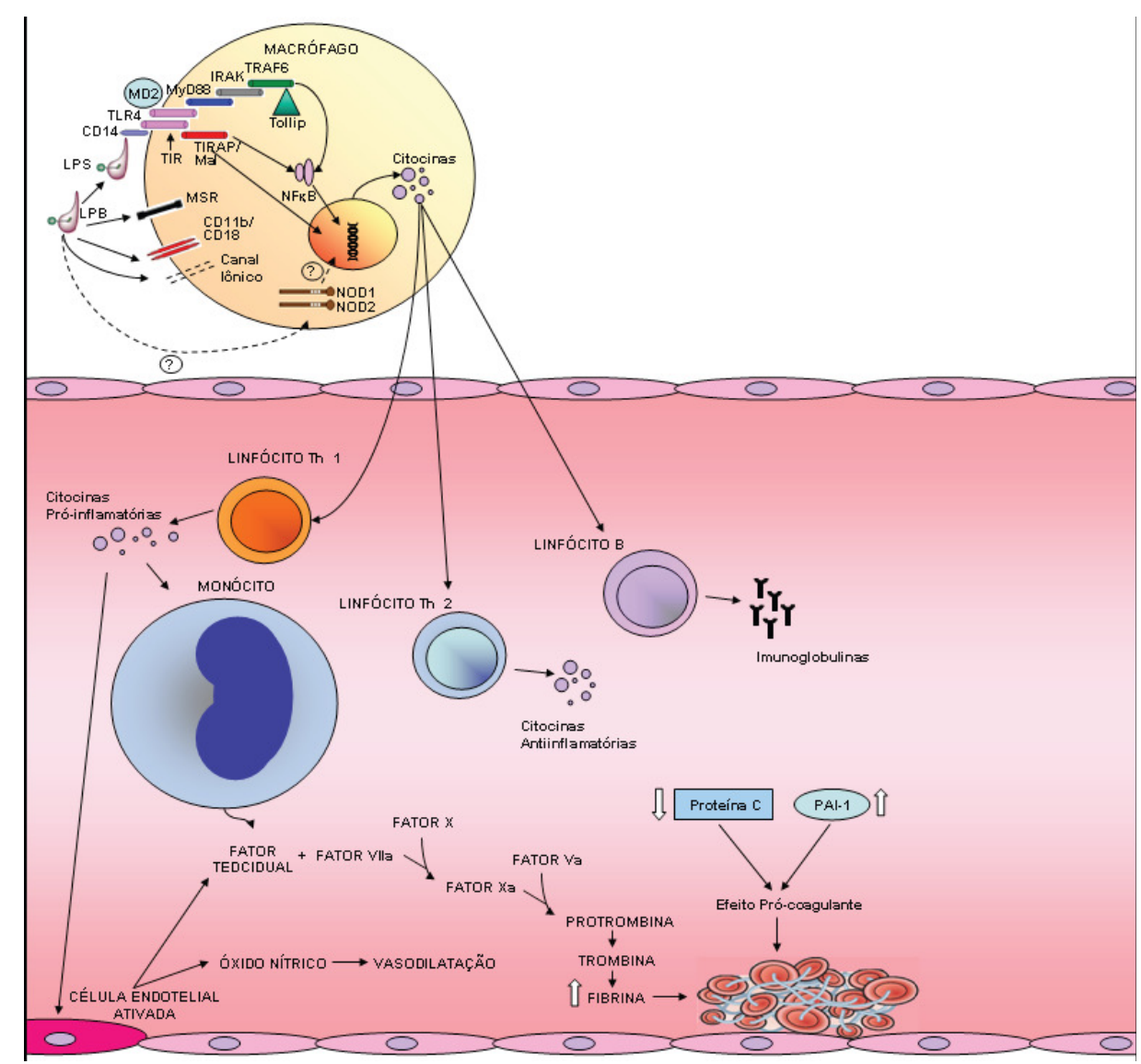

Figura 11: Mecanismos Fisiopatológicos da Sepse. A figura mostra a seqüência de eventos implicados na formação das alterações imunes, inflamatórias e da coagulação na sepse. Fonte: HENKIN, et al, 2009.

Quase todos os mediadores inflamatórios agem diretamente no endotélio vascular. Os efeitos locais destas citocinas envolvem o recrutamento de células fagocitárias, essencial para a eliminação dos microrganismos, enquanto que os efeitos sistêmicos de seus altos níveis na circulação causam dano ao hospedeiro, o que ocorre na sepse e no choque séptico (PEREIRA Jr. et al, 1998).

Uma das alterações mais importantes da sepse e do choque séptico é a adesão de leucócitos nas células endoteliais (BRADY et al, 2000). A adesão leucocitária é estimulada pela ação das citocinas inflamatórias, especialmente IL-1 e FNT- $\alpha$. Quando as células endoteliais são expostas às citocinas ou acometidas por isquemia, expressam glicoproteínas chamadas moléculas de 
SILVEIRA, S.R., FERREIRA, L.F.L. e LAGE, M.H.H. Fisiopatologia da sepse: revisão de literatura. PUBVET, Londrina, V. 8, N. 9, Ed. 258, Art. 1709, Maio, 2014.

adesão leucócito endotélio (ELAM), que são responsáveis pela ligação dos receptores nos leucócitos (PURVIS; KIRBY, 1994), promovendo a transmigração de polimorfonucleares e monócitos em direção ao tecido lesado. Nestes locais, altas concentrações de IL-1 e IL-8 exercem efeito quimioatrativo e dirigem os fagócitos para o local da lesão (VERONESI; FOCACCIA, 2001).

O resultado da expressão das moléculas de adesão endoteliais é o aumento da migração e manutenção da atividade celular no tecido lesado, levando à perda da capacidade homeostática do endotélio e passagem de líquido, células e proteínas para o espaço intersticial, formando edema (NYSTRON, 1998).

Após ativação do complemento, os neutrófilos demonstram deformabilidade diminuída, o que favorece seqüestro adicional na microcirculação. Aderência ao endotélio, interação com LPS e a presença de complemento aumentam a capacidade oxidativa dos neutrófilos. A liberação de radicas de oxigênio reativos e enzimas lissosômicas resultam em lesão endotelial e tecidual (Figura 12) (REED, 1998).

Os mediadores e produtos liberados da atividade dos neutrófilos e das células endoteliais incluem os metabólitos do ácido araquidônico, radicais livres de oxigênio, óxido nítrico e fator de ativação plaquetária (MIAO et al., 2002). 
SILVEIRA, S.R., FERREIRA, L.F.L. e LAGE, M.H.H. Fisiopatologia da sepse: revisão de literatura. PUBVET, Londrina, V. 8, N. 9, Ed. 258, Art. 1709, Maio, 2014.

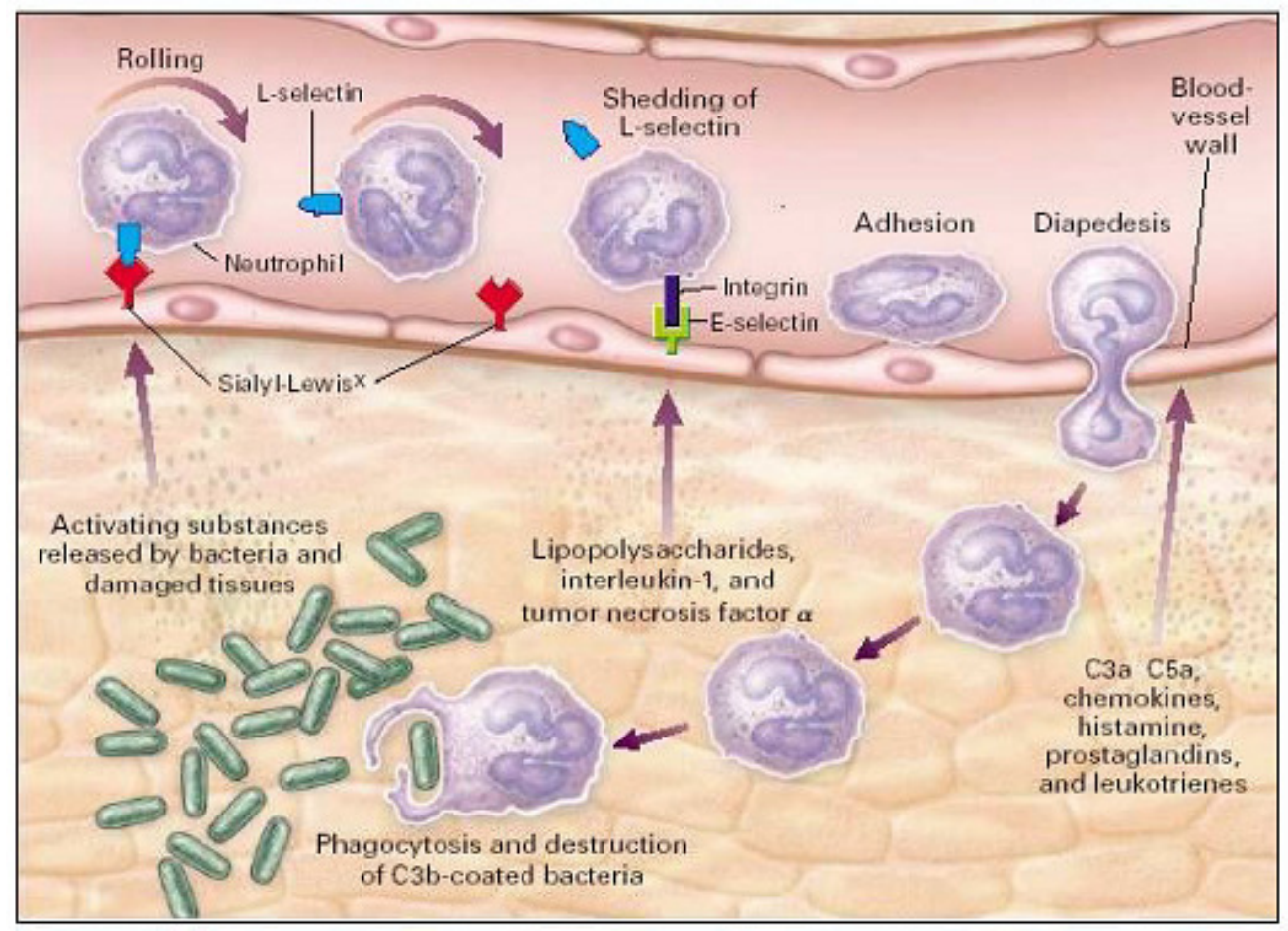

Figura 12: Moléculas de adesão que desempenham papel na migração de neutrófilos através do endotélio ao local de infecção. Fonte: RUSSEL, 2006.

Os complexos LPS-LPB podem desempenhar importante papel na cinética, no transporte e nas interações celulares de endotoxinas absorvidas sistemicamente. O LPS exerce efeitos prejudiciais sobre o hospedeiro por indução direta e indireta de resposta inflamatória exagerada. Diretamente, o LPS ativa o complemento, a coagulação e as cascatas fibrinolíticas. As populações de células hospedeiras, incluindo linfócitos, neutrófilos, células endoteliais, plaquetas e, mais importante, células mononucleares, são ativadas por meio de interações específicas e inespecíficas de LPS (REED, 1998).

A lesão endotelial causada por LPS e por neutrófilos ativados resulta na liberação de tromboplastina e na exposição de colágeno subendotelial que ativam a cascata intrínseca e extrínseca da coagulação, respectivamente. As células endoteliais ativadas por LPS e citocinas contribuem para alterações na coagulação através da produção de atividade pró-coagulante semelhante aos 
SILVEIRA, S.R., FERREIRA, L.F.L. e LAGE, M.H.H. Fisiopatologia da sepse: revisão de literatura. PUBVET, Londrina, V. 8, N. 9, Ed. 258, Art. 1709, Maio, 2014.

fatores teciduais, ativador de plasminogênio tecidual e inibidor/ativador de plasminogênio (REED, 1998).

A coagulação é iniciada através da expressão do fator tecidual (FT) na superfície das células endoteliais e monócitos, um evento que pode ser desencadeado por produtos bacterianos como endotoxinas e componentes da superfície celular ou por citocinas pró-inflamatórias. O LPS estimula as células endoteliais a produzir o $\mathrm{FT}$, o qual na superfície celular ativa o fator VII, resultando no complexo fator VIIa e FT que converte o fator X em Xa. Em conjunto com o fator $\mathrm{Va}$, o fator $\mathrm{Xa}$ converte a protrombina em trombina, o que por sua vez resulta na clivagem do fibrinogênio em fibrina. Embora a deposição de fibrina tenha papel importante na homeostasia e na localização de microorgranismos, a coagulação intravascular impede a chegada de oxigênio aos tecidos e pode induzir nova lesão inflamatória. Por sua vez, o receptor da trombina ativa o NFKB, acarretando a transcrição de genes de mediadores inflamatórios e síntese de óxido nítrico (HENKIN et al, 2009).

A ação do FNT- $\alpha$ sobre as células endoteliais resulta em aumento da permeabilidade capilar por formação de orifícios e aumento do espaço intercelular, levando a extravasamento de líquidos e células para o interstício. A atividade pró-coagulante é estimulada através da redução da síntese de trombomodulina e aumento da síntese do PAI-1, com incremento da tendência à trombose intravascular. Esta atividade pró-coagulante é mais acentuada nos locais em que o endotélio está se multiplicando, como nos vasos de tumores e locais de inflamação. A estimulação das células endoteliais acarreta maior produção de óxido nítrico, que tem potente ação relaxante sobre a musculatura lisa dos vasos sanguíneos, levando a vasodilatação. Os efeitos descritos, aumento da permeabilidade capilar, vasodilatação e atividade prócoagulante, são mantidos, modulados e amplificados por outros mediadores, como os derivados do ácido araquidônico, fatores da coagulação, cininas, entre outros (VERONESI; FOCACCIA, 2001).

Após as barreiras naturais da pele e mucosas, os monócitos e macrófagos constituem a primeira linha de defesa contra infecções (AKAMINE 
SILVEIRA, S.R., FERREIRA, L.F.L. e LAGE, M.H.H. Fisiopatologia da sepse: revisão de literatura. PUBVET, Londrina, V. 8, N. 9, Ed. 258, Art. 1709, Maio, 2014.

et al, 1994). Estas células liberam citocinas pela presença das endotoxinas ao mesmo tempo em que fagocitam os microrganismos presentes no foco da infecção. Isto causa um amento do consumo de oxigênio pelos macrófagos e a produção de radicais livres de hidrogênio, juntamente com proteases e hidrolases, que são capazes de gerar danos a esses patógenos. Os macrófagos ativados também secretam muitos mediadores inflamatórios, tais como leucotrienos e PAF, que são ativos em células distantes e amplificam a reação inflamatória (PEREIRA Jr et al., 1998).

$\mathrm{Na}$ segunda fase, os mediadores são liberados em pequena quantidade, para acentuar os efeitos locais, reunindo macrófagos e plaquetas, havendo também, estimulação na produção do fator de crescimento. Inicia-se uma fase aguda de resposta controlada por diminuição simultânea de mediadores próinflamatórios, e de antagonistas de liberação endógena (PURVIS; KIRBY, 1994).

\section{3- Estágio III}

Nos últimos anos, progressos em biologia celular e molecular mostraram que a agressão bacteriana ou de seus subprodutos (endotoxinas, LPS), não são os únicos responsáveis pela deterioração clínica dos pacientes em choque e que a resposta do hospedeiro desempenha papel importante nos diferentes tipos de agressões, quer infecciosas ou não. A identificação de mediadores e dos mecanismos envolvidos na produção das alterações fisiológicas, metabólicas e celulares, o papel das células endoteliais, das moléculas de interação célula-endotélio, do endotélio do trato intestinal são de grande interesse, porque estão envolvidas na perda da capacidade de homeostase do organismo (SALLES et al., 1999).

Nos estágios I e II temos todas as reações protetoras e promotoras que evoluem continuamente até a reparação da lesão, combate à infecção e recuperação da homeostase. Contudo, pode haver um estágio III, situação em que a homeostase não se restabelece. Esta falha promove uma reação 
SILVEIRA, S.R., FERREIRA, L.F.L. e LAGE, M.H.H. Fisiopatologia da sepse: revisão de literatura. PUBVET, Londrina, V. 8, N. 9, Ed. 258, Art. 1709, Maio, 2014.

sistêmica maciça, onde os efeitos dos mediadores são predominantemente destrutivos. Desencadeiam-se reações catastróficas sustentadas por ativação do sistema retículo-endotelial, com perda da integridade das membranas celulares, lesões de vários órgãos, descontrolada vasodilatação sistêmica com conseqüente diminuição da resistência vascular periférica. O resultado, entre outros, é a hipotensão e o exagerado extravasamento de líquidos para o interstício, com contração dos espaços extracelular e intracelular. Agrava estes eventos o fato de que, no estágio III da resposta inflamatória, o miocárdio sofre notável depressão de sua contractilidade, sob efeito da produção parácrina de óxido nítrico, provavelmente do endotélio vascular (PURVIS; KIRBY, 1994).

A resposta inflamatória não-controlada, iniciada pelas citocinas e outros mediadores, exerce seus efeitos finais no nível do endotélio microvascular, o qual participa ativamente da patogênese da inflamação, funcionando como uma interface intermediária na sinalização dos neutrófilos circulantes. Nesse sentido, o endotélio ativado, de maneira moderada, é benéfico, mas ativado em excesso pode levar à oclusão microvascular e à disfunção vascular grave (LIVINGSTON; MOSENTHAL; DEITCH, 1995).

Deve-se fazer uma distinção entre os efeitos locais (parácrinos) das citocinas e as conseqüências de seus altos níveis na circulação sistêmica. Os efeitos locais envolvem o recrutamento de células fagocitárias, essencial para a eliminação dos microrganismos, enquanto que os efeitos sistêmicos causam danos ao hospedeiro, principalmente no caso do mediador FNT- $\alpha$, que parece ser o mediador chave no choque séptico (PEREIRA Jr.et al, 1998).

$\mathrm{Na}$ sepse ocorrem alterações do metabolismo celular que afetam o metabolismo lipídico, dos carboidratos e proteínas. A oferta inadequada de oxigênio aos tecidos em decorrência da queda do fluxo sanguíneo nos capilares e da redução do débito cardíaco contribui para o aumento do metabolismo anaeróbico e a hiperlactatemia. Entretanto, mesmo na presença de uma oferta adequada de oxigênio, podem ocorrer extração e utilização ineficaz de oxigênio a nível mitocondrial, levando alguns pesquisadores a especular que haveria 
SILVEIRA, S.R., FERREIRA, L.F.L. e LAGE, M.H.H. Fisiopatologia da sepse: revisão de literatura. PUBVET, Londrina, V. 8, N. 9, Ed. 258, Art. 1709, Maio, 2014.

uma hibernação celular, tal qual a que ocorre na isquemia miocárdica. Uma das principais consequências da disfunção mitocondrial é a redução na produção de ATP, a qual pode persistir mesmo após a restauração da oferta de substratos, condição conhecida como hipóxia citopática (HENKIN et al, 2009).

\section{INFECÇÃO}

(Bactéria, vírus, fungos, etc)

\section{MOLÉCULAS DESENCADEANTES}

(Endotoxinas, exotoxinas, ácido teicóico, etc)

\section{MEDIADORES PRIMÁRIOS}

$$
\text { (FNT- } \alpha, \text { IL-1, C5a, etc) }
$$

\section{$\downarrow$}

Ativação da resposta imune celular e humoral

\section{MEDIADORES SECUNDÁRIOS}

(Citocinas, fatores do complemento, prostanóides,

PAF, espécies ativas de oxigênio, etc)

\section{CHOQUE}

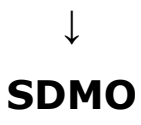

Figura 13 - Principais passos na patogênese da sepse, levando ao choque séptico e à síndrome da disfunção de múltiplos órgãos. Fonte: PERREIRA Jr.et al, 1999.

\section{6- CONSIDERAÇÕES FINAIS}

A resposta inflamatória na sepse envolve vários mediadores, sendo que estes, muitas vezes, são redundantes em suas características estruturais e 
SILVEIRA, S.R., FERREIRA, L.F.L. e LAGE, M.H.H. Fisiopatologia da sepse: revisão de literatura. PUBVET, Londrina, V. 8, N. 9, Ed. 258, Art. 1709, Maio, 2014.

funcionais. A resposta inflamatória pode ser regulada em vários níveis, desde a produção de citocinas até a produção de moléculas de adesão. Estas informações são clinicamente relevantes e podem explicar muitos dos achados patológicos da sepse, além de nos permitir entender por que a utilização de agentes dirigidos a apenas um ponto da resposta imune tem sido falha na aplicação clínica.

O conhecimento profundo da fisiopatologia da sepse e dos mecanismos básicos envolvidos na resposta inflamatória do hospedeiro é de extrema importância já que o reconhecimento precoce e um tratamento adequado são fundamentais para prevenir a cascata de eventos que culmina com o choque e falha orgânica múltipla.

Apesar de grandes avanços terem ocorrido para a compreensão dos mediadores endógenos e seus papéis na resposta inflamatória durante a sepse, ainda não se demonstrou, inequivocamente, a relativa contribuição de cada mediador inflamatório na letalidade resultante do choque séptico. Dessa forma, é de extrema importância o estudo da resposta inflamatória durante a sepse para que no futuro ocorra redução da alta mortalidade decorrente dessa importante entidade clínica.

\section{REFERÊNCIAS BIBLIOGRÁFICAS}

ABBAS, A.K.; LICHTMAN, A.H.; PILLAI, S. Cellular and Molecular Immunology. 6 ed. Saunders Elsevier, 2007.

AKAMINE, N. et al. Choque séptico. In: KNOBEL E. Condutas no paciente grave. São Paulo:Atheneu, 1994. Cap. 15, p.175-210.

BATLOUNI, M.; RAMIRES, J.A.F. Importância do endotélio na doença arterial coronária e na aterogênese. Arquivo Brasileiro de Cardiologia, v.62, p.255-70, 1994.

BELLOMO, R. The cytokine network in the critically ill. Anesthesiology Intensive Care, v.20, p.288, 1992.

BEUTLER, B.; POLTORAK, A. Sepsis and evolution of the innate immune response. Critical Care Medicine, v. 29, p.2-7; jul. 2001.

BONE, R.C. et al. Definitions for sepsis and organ failure and guidelines for the use of innovative therapies in sepsis. ACCP/SCCM Consensus Conference Committee, v.101, p.1644$1655,1992$. 
BONE, R.C. The pathogenesis of sepsis. Annals Intern Medicine, v.115, n.6, p.457-469, sept. 1991.

BONE, R.C. et al. Sepsis syndrome : a valid clinical entity. Critical Care Medicine, v.17, n.5, p.389-393, may 1989.

BRADY, C.A. et al. Severe sepsis in cats: 29 cases (1986-1998). Journal of the American Veterinary Medical Association, v.217, n.4, p.531-535, aug. 2000.

CARLOS, M.M.L.; FREITAS, P.D.F.S. Estudo da cascata de coagulação sanguínea e seus valores de referência. Acta Veterinária Brasílica, v.1, n.2, p.49-55, 2007.

CRUVINEL, W.M. et al. Aspectos celulares e moleculares da inflamação. Revista Brasileira de Medicina, p.66-81, abr. 2009.

DAL NOGARE, A. Southwestern internal medicine: septic shock. American Journal of the Medical Sciences, v.302, p.50, 1991.

FARRAR, M.A.; SCHREIBER, R.D. The molecular cell biology of interferond and its receptor. Annual Review Immunology, v.11, p.571, 1993.

FRANCO, R.F. Fisiologia da coagulação, anticoagulação e fibrinólise. Simpósio Medicina e Trombose, Ribeirão Preto, v.34, p.229-237, jul./dez. 2001.

GARCIA NAVARRO, C.E.K. Manual de Hematologia Veterinária. 2 ed. São Paulo:Varela, 2005.

GEORGE, J.N., SHATTIL, S.J. The clinical importance of acquired abnormalities of platelet functions. New England Journal of Medicine, v.324, p.27- 39, 1991.

HAUSER, B. et.al. Nitric Oxide Synthase Inhibition in Sepsis? Lessons Learned from LargeAnimal Studies. Anesthesia \& Analgesia, v.101, p.488-498, 2005.

HENKIN, C.S. et al. Sepse : uma visão atual. Scientia Medica, v.19, n.3, jul./dez. 2009.

ITURRY-YAMAMOTO, G.R.; PORTINHO, C.P. Sistema complemento: ativação, regulação e deficiências congênitas e adquiridas. Revista da Associação Médica Brasileira, v.47, n.1, p.41-51, 2001.

JANEWAY, C.A. et al. Imunobiologia: o sistema imune na saúde e na doença. 5 ed. Porto Alegre: Artmed, 2002.

JEAN-BAPTISTE, E. Cellular mechanisms in sepsis. Intensive Care Medicina, v.22, n.2, p.63$72,2007$.

KNOBEL, E. Óxido nítrico e sepse. Arquivo Brasileiro de Cardiologia, v.67, n.4, p.263-266, 1996.

LIVINGSTON, D.; MOSENTHAL, A.; DEITCH, E. Sepsis and multiple organ dysfunction syndrome: a clinical-mechanistic overview. New Horizons, v.3, n.2, p.257-266, may 1995.

LEHNE, R. Pharmacology for Nursing Care. 3 ed. Philadelphia: W. B. Saunders, 2000.

LEVI, M; CATE, H.T.; POLL, T.V.D. Pathogenesis of disseminated intravascular coagulation in sepsis. Journal of the American Medical Association, v.270, n.8, p.975-979, 1993.

LYNN, W.A.; GOLENBOCK, D. Lipopolysaccharide antagonists. Immunology Today, v.13, p. 271-76, 1992.

MACHADO, P.R.L. et al. Mecanismos de resposta imune às infecções. Anais Brasileiro de Dermatologia, Rio de Janeiro, v.79, n.6, p.647-664, nov./dez. 2004.

MIAO, C.H. et al. Pharmacodynamics and pharmacokinetics of inhaled nitric oxide in dogs with septic acute respiratory distress syndrome. p.278-84, mar. 2002.

Acta Pharmacologica Sinica, v.23, n.3, 
MOSMANN, T.R. Properties and functions of interleukin-10. Advances in Immunology, v.56, p.1-26, 1994.

NYSTROM, P.O. The systemic inflammatory response syndrome: definitions and aetiology. Journal Antimicrob Chemother, v.41, p.1-7, jan. 1998.

OPAL, S.M. The host response to endotoxin, antilipopolysaccharide strategies, and the management of severe sepsis. Internacional Journal of Medical Microbiology, v.297, n.5, p.365-77, 2007.

PEREIRA JUNIOR, G.A. et al. Fisiopatologia da sepse e suas implicações terapêuticas. Simpósio Medicina Intensiva: I infecção e choque, Ribeirão Preto, v.31, p.349-362, jul./set. 1998.

PINSKY, M.R.; TEBOUL, J.L. Assessment of indices of preload and volume responsiness. Current Opinion in Critical Care, v.11, p.235-239, 2005.

PORTH, C.M. Fisiopatologia. In: SOMMER, C. 6.ed. Rio de Janeiro: Guanabara Koogan S.A., 2002. Cap. 18, p. 318-342.

PURVIS, D.; KIRBY, R. Systemic inflammatory response syndrome: septic shock. Veterinary Clinical North America Small Animals Practice, v.24, n.6, p.1225-47, nov. 1994.

REED, S.M. Medicina Interna Eqüina. 1.ed. Rio de Janeiro: Guanabara Koogan S.A., 1998. Cap. 12, p.550-554.

RUSSEL, J.A. Management of Sepsis. New England Journal of Medicine, v.355, p.16991713, 2006.

SANCHEZ, A.P. et al. Respuesta inflamatória sistêmica inespecífica infecciosa y no infecciosa em los pacientes críticos. Revista Cubana de Medicina Militar, v.33, n.1, 2004.

SILVA, E.; FRIEDMAN, G. Sepse. São Paulo: Atheneu, 1999. 444 p.7 v.

SILVA, E.; VICENT, J.L. Síndrome da resposta inflamatória sistêmica (SIRS), sepse, choque séptico e síndrome da disfunção múltipla dos órgãos: definições e implicações clínicas. Disponível em: < http://www.vet.ufg.br/uploads/files/1-SIRS.pdf >. Acesso em: 02 jan. 2010.

SILVA, W.D.; MOTA, I. Imunologia básica aplicada. 5 ed. Rio de Janeiro: Guanabara Koogan, 2003.

SALLES, M.J.C. et al. Síndrome da resposta inflamatória sistêmica/sepse: revisão e estudo da terminologia e fisiopatologia. Revista da Associação Médica Brasileira, São Paulo, v. 45, n.1, jan./mar. 1999.

SRISKANDAN, S.; COHEN, J. The Pathogenesis of Septic Shock. Journal of Infection, v.30, p.201-206, 1995.

TAKAHIRA, R.K. Hemostasia veterinária. Botucatu, 2005. Disponível em:< http://www.fmvz.unesp.br/Eventos/Especializacao/disciplinas/labora torioclinico/hemostasia introducao.pdf > Acesso em: 05 dez. 2009.

UTIYAMA, S.R.R.; REASON, I.T.M.; KOTZE, L.M.S. Conceitos atuais na ativação do sistema complemento e suas propriedades biológica. Revista brasileira de análises clínicas, v.36, n.3, p.183-188, 2004.

VAN DER POLL, T. et al. Regulation of interleukin 10 release by tumor necrosis factor in humans and chimpanzees. Journal of Experimental Medicine, v.180, n.5, p.1985-1988, 1994.

VERONESI, R., FOCACCIA, R. Tratado de Infectologia. In: DIAMENT, D.; LOMAR, A.V. 2.ed. São Paulo: Atheneu, 2001. Cap. 71, p.888- 904. 
VICENT, J.L. et al. Effects of nitric oxide in septic shock. American Journal and Critical Care Medicine, v.161, p.1781- 1785, 2000.

Respiratory

VOSS, R. et al. Activation and inhibition of fibrinolysis in septic patients in an internal intensive care unit. British Journal of Haematology, v.75, p.99-105,1990.

WARD, P.A. Sepsis, apoptosis and complement. Biochemical Pharmacology, v.76, p.13831388, 2008.

WHEELER A, P.; BERNARD, G.R. Treating patients with severe sepsis. New England Journal of Medicine, v.340, n.3, p. 207-214, 1999.

WILLIAMS, G.; GIROIR, B. Regulation of cytokine gene expression: tumor necrosis factor, interleukin-1, and the emerging biology of citokyne receptors. New Horizons, v.3, p.276, 1995.

WRIGHT, S.D.; RAMOS, R.A.; TOBIAS, P.S. et al. CD14, a receptor for complexes of lipopolysaccharide (LPS) and LPS binding protein. Science, v.249, n.4975, p.1431-1433, sept. 1990. 